\title{
Pathophysiology of human ventilatory control
}

\author{
Jerome A. Dempsey, Curtis A. Smith \\ Number 6 in the series "Physiology in Respiratory Medicine" \\ Edited by R. Naeije, D. Chemla, A. Vonk-Noordegraaf and A.T. Dinh-Xuan
}

\author{
Affiliation: \\ John Rankin Laboratory of Pulmonary Medicine, University of Wisconsin-Madison, Madison, WI, USA.
}

\section{Correspondence:}

Jerome A. Dempsey, University of Wisconsin-Madison, 1300 University Ave, Room 4245 MSC, Madison, WI 53706-1532, USA.

E-mail: jdempseyवwisc.edu

\begin{abstract}
We review the substantial recent progress made in understanding the underlying mechanisms controlling breathing and the applicability of these findings to selected human diseases. Emphasis is placed on the sites of central respiratory rhythm and pattern generation as well as newly described functions of the carotid chemoreceptors, the integrative nature of the central chemoreceptors, and the interaction between peripheral and central chemoreception. Recent findings that support critical contributions from cortical central command and muscle afferent feedback to exercise hyperpnoea are also reviewed. These basic principles, and the evidence supporting chemoreceptor and ventilatory control system plasticity during and following constant and intermittent hypoxaemia and stagnant hypoxia, are applied to: 1) the pathogenesis, consequences and treatment of obstructive sleep apnoea; and 2) exercise hyperpnoea and its control and limitations with ageing, chronic obstructive pulmonary disease and congestive heart failure.
\end{abstract}

@ERSpublications

We review control of breathing in humans and how new findings lead to novel treatments in sleep apnoea, CHF and COPD http://ow.ly/weJ7A

\footnotetext{
Previous articles in this series: No 1: Naeije R, Vachiery J-L, Yerly P, et al. The transpulmonary pressure gradient for the diagnosis of pulmonary vascular diseases. Eur Respir J 2013; 41: 217-223; No. 2: Hughes JMB, van der Lee I. The TL,NO/ TL,CO ratio in pulmonary function test interpretation. Eur Respir J 2013; 41: 453-461; No. 3: Vonk-Noordegraaf A, Westerhof N. Describing right ventricular function. Eur Respir J 2013; 41: 1419-1423; No. 4: Hamzaoui O, Monnet X, Teboul J-L. Pulsus paradoxus. Eur Respir J 2013; 42: 1696-1705; No. 5: Prisk GK. Microgravity and the respiratory system. Eur Respir J 2014; 43: 1459-1471.
}

Received: March 122014 | Accepted after revision: April 172014 | First published online: June 122014

Support statement: Original research findings of the authors reported in this review were supported by NHLBI (grant numbers HL-15469 (J.A. Dempsey) and HL-50531 (C.A. Smith)), the American Heart Association and the US Veterans Administration.

Conflict of interest: None declared.

Copyright @ERS 2014 


\section{Brief summary of key points}

Key feedback mechanisms originating in sensitised chemoreceptors and locomotor muscles contribute importantly to abnormal ventilatory control during exercise and sleep in chronic obstructive pulmonary disease (COPD), congestive heart failure (CHF) and obstructive sleep apnoea (OSA). Reducing the excessive hypersensitivity of these reflex receptors and their central projections may play major roles in the treatment of exercise hyperventilation, dyspnoea,sleep apnoea and autonomic imbalance.

In healthy humans, ventilation is tightly controlled by a system that is concerned with both the precise constancy of alveolar and arterial blood gases and acid-base status as well as with minimising the work and metabolic cost of each breath. Breathing must remain a largely involuntary act of which we are unaware. To this end, a three-component system is required, consisting of a central medullary rhythm/pattern generator and integrator, extensive sensory inputs to the central integrator and, finally, the precise synchronous distribution of motor output to the respiratory musculature of the upper airway as well as the chest and abdominal walls. Our understanding of how all this is accomplished with such high precision and efficiency in the healthy human has made significant progress in the past two decades. In this brief review, we summarise a few of these accomplishments in the basic science of ventilatory control and how these findings have impacted our understanding and treatment of selected clinical problems.

\section{Central rhythm/integration}

The advent of the in vitro neonatal rodent brainstem preparation has allowed for precise identification of specific medullary sites for separate but coupled rhythm generation or "oscillators". These neurons reside in the pre-Bötzinger complex for inspiration and in the parafacial respiratory group for (active) expiration [1]. Of the several models proposed for producing respiratory rhythm, the most promising appears to be a hybrid model that combines the emergent properties of networks of synaptic connections and intrinsic membrane properties of individual neurons together with independent pacemaker-type neurons [2, 3]. In order for the underlying respiratory rhythm to generate a physiological breathing pattern, a highly complex coordinated process is required, wherein the pre-motor and motor respiratory neuronal activities influence the timing and amplitude of a broad array of respiratory muscles, including those controlling upper airway resistance as well as the respiratory pump. Research into how abnormalities or mutations of the medullary neuronal networks responsible for rhythm and pattern generation may impact human disease is in its infancy. However, abnormal breathing patterns, often with $\mathrm{CO}_{2}$ retention in waking and especially in sleep, have been documented in neurodegenerative diseases such as Parkinson's disease, amyotrophic lateral sclerosis, post-polio syndrome with bulbar involvement and multiple system atrophy, all of which have been linked to deficits in neurons in the pre-Bötzinger complex, pontine raphe and adjacent areas [4-6]. Furthermore, the pre-Bötzinger complex has been identified as a major site of action mediating the markedly depressive effects of opiate agonists on respiratory rhythm and the reversal of this depressive effect via $\mu$-opioid antagonists [7, 8].

\section{Chemoreception}

The past decade has provided the most significant advances in understanding peripheral and central chemoreceptor function since the discovery of carotid chemoreceptor function in the 1930s by the Nobel laureate Heymans [9] and Mitchell and Loeschke's identification of medullary chemosensitive areas in the 1960s [10]. Here we provide a summary of the key developments most relevant to human pathophysiology.

\section{Carotid body chemoreception}

We now know that hypoxia triggers sensory input from the carotid body by inhibiting oxygen-sensitive potassium channels in the glomus cells of the carotid body via several mechanisms, including release of gaseous transmitters $\left(\mathrm{NO}, \mathrm{CO}, \mathrm{H}_{2} \mathrm{~S}\right)$, AMP-activated protein kinases and/or reactive oxygen species $[11,12]$ (fig. 1). Basic knowledge of these mechanisms will prove invaluable in the pursuit of pharmacological approaches to inhibiting or stimulating carotid chemoreceptor function in some chronic diseases (also discussed in the section on Plasticity). It is now clear that carotid bodies are polymodal receptors responsive to several circulating stimuli beyond just $\mathrm{O}_{2}, \mathrm{CO}_{2}$ and $\mathrm{H}^{+}$, such as $\mathrm{K}^{+}$, noradrenaline, temperature and osmolarity as well as glucose and insulin. Further, reductions in carotid body blood flow (in addition to changes in arterial oxygen tension) also provide powerful carotid body stimulation and remodelling over time $[13,14]$. On the effector side, in addition to ventilation, the carotid bodies are now well established as key mediators of sympathetic vasoconstrictor outflow and this mediation occurs through medullary pathways that operate independently of the respiratory rhythm generating network [15]. 


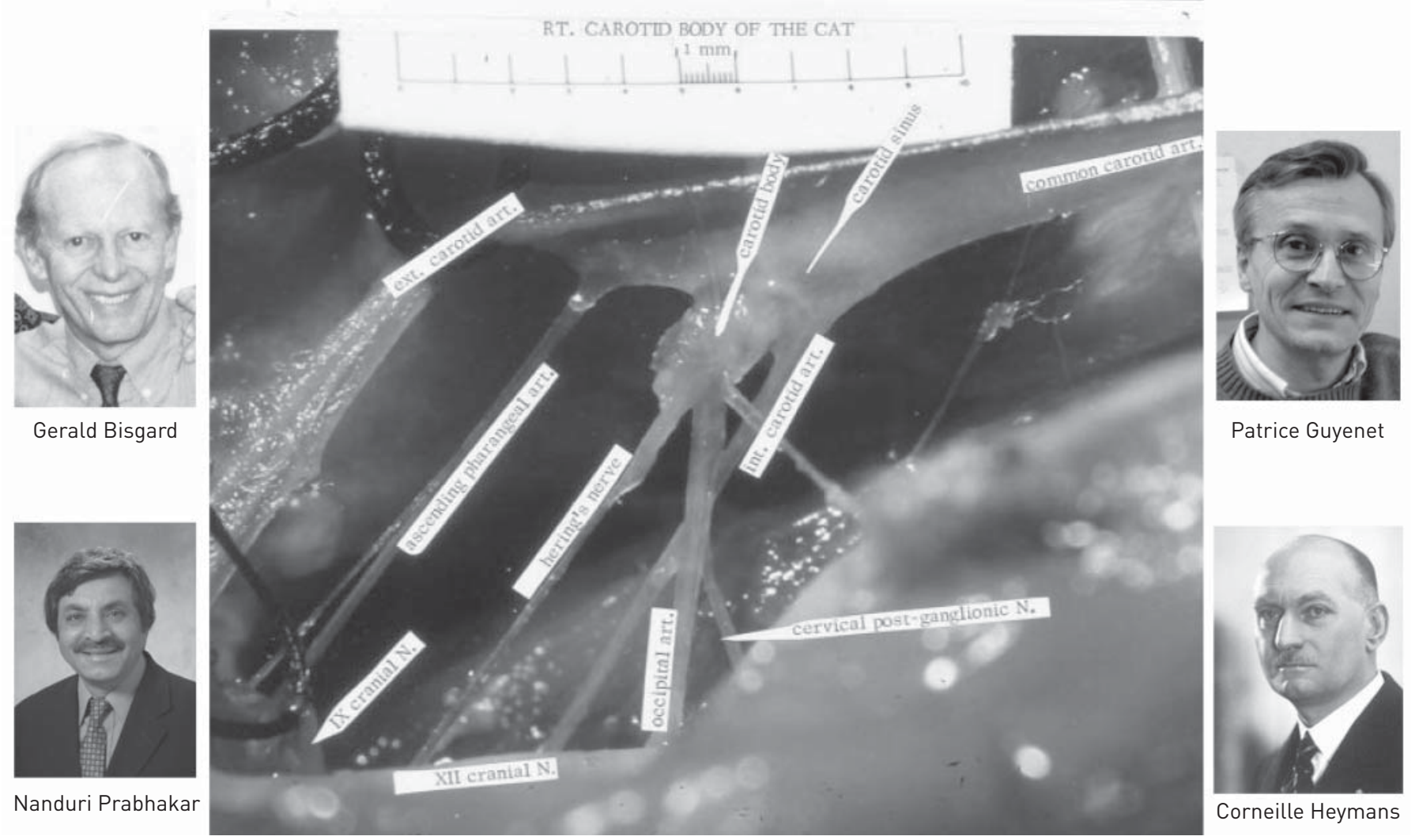

FIGURE 1 Carotid chemoreceptor in the cat. The heart is to the right and brain to the left, with the carotid chemoreceptor located at the bifurcation of the common carotid artery, $<15 \mathrm{~s}$ circulation time from the lung. Note that the human carotid body is about $2-7 \mathrm{~mm}$ in diameter, and is innervated by the carotid sinus nerve (labelled here as Hering's nerve), and vagal and sympathetic nerves of the superior cervical ganglion. The perfusion of the carotid chemoreceptor is the largest of any organ in the body, i.e. $\sim 2000 \mathrm{~mL} \cdot \mathrm{min}^{-1}$ per $100 \mathrm{~g}$ tissue. $\mathrm{N}$ : nerve; ext.: external; int.: internal; art.: artery. Photographs show Nobel laureate Corneille Heymans (1892-1968), who first described the function of the carotid chemoreceptor in the 1930s; Patrice Guyenet, who recently defined the neural pathways involved in peripheral/central chemoreceptor interdependence; and Gerald Bisgard and Nanduri Prabhakar, who have both made important contributions over the past two decades to our understanding of carotid chemoreceptor $\mathrm{O}_{2}$ sensing mechanisms and especially its plasticity. The photograph of the carotid chemoreceptor is reproduced courtesy of Edward H. Vidruk (University of Wisconsin-Madison, Madison, WI, USA).

\section{Peripheral/central chemoreceptor interdependence and central chemoreceptors as a site of convergence}

Several $\mathrm{H}^{+}$sensitive sites in the medulla and midbrain have been identified that stimulate breathing $[16,17]$. However, the parafacial retrotrapezoid nucleus (RTN), which is characterised by glutamatergic interneurons that strongly express Phox $2 \mathrm{~b}$, is likely to be the major site of central $\mathrm{CO}_{2}$ chemoresponsiveness. Phox $2 \mathrm{~b}$ has also been identified as a key gene product participating in early embryonic development of the autonomic nervous system [18]. Moreover, a Phox $2 b$ mutation has been identified as a predisposing genotype underlying congenital central hypoventilation syndrome, in which severe hypoventilation and apnoea routinely attend administration of sedatives and anaesthetics or occur with sleep onset [19]. The RTN chemosensors also appear to serve as important sites for integration of several stimuli, as these neurons are significantly modulated by inputs from carotid chemoreceptors, vagally mediated pulmonary stretch receptors and the hypothalamus [18]. Recent evidence (using c-FOS immunoreactivity) has shown these RTN Phox $2 \mathrm{~b}$ neurons are also activated by acute exercise in the rodent [20], indirectly suggesting potential participation of RTN chemosensitive neurons in the "central command" stimulus to exercise hyperpnoea (also discussed in the section on Exercise hyperpnoea in health and disease).

The Phox $2 \mathrm{~b}$ neurons are part of an uninterrupted chain of neurons in a circuit that includes the carotid bodies and their afferents as well as the nucleus of the tractus solitarius projections to the RTN [18]. The functional consequences of this linkage are that stimulation of the peripheral chemoreceptors enhances the slope of the central $\mathrm{CO}_{2}$ ventilatory response; conversely, inhibition of the carotid bodies reduces the slope of the central $\mathrm{CO}_{2}$ response (fig. 2a and b) [21]. Other studies using different experimental preparations with isolated carotid and/or brainstem perfusions also show interdependence between the chemoreceptors, but opinions vary as to whether this interdependence is hypo- or hyperadditive in its effect on ventilation 

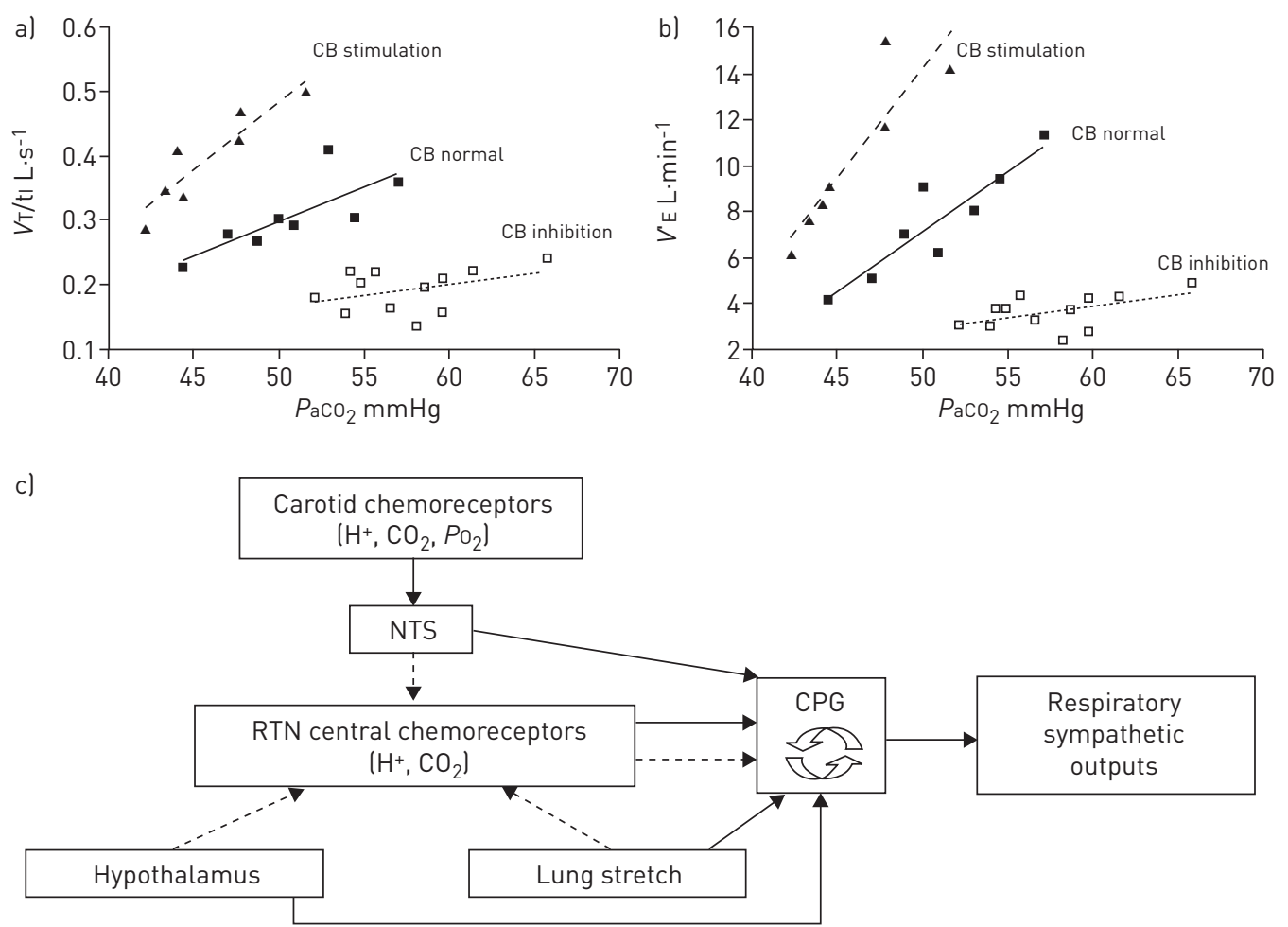

FIGURE 2 Hyperadditive effects of carotid chemoreceptor input on central $\mathrm{CO}_{2}$ response. In a canine, the carotid chemoreceptor is denervated on one side. The remaining carotid chemoreceptor is vascularly isolated from the systemic and cerebral circulation and perfused extracorporeally. The central chemoreceptor response to $\mathrm{CO}_{2}$, by itself, is determined by steady-state inhalation of $\mathrm{CO}_{2}$-enriched air. Animals were studied during quiet wakefulness. Note that, when the isolated carotid body $(\mathrm{CB})$ is inhibited $\left(\mathrm{CB} \mathrm{CO}_{2}\right.$ tension $\left(\mathrm{PCO}_{2}\right)=20$ Torr and $\mathrm{CB}$ oxygen tension $\left(\mathrm{PO}_{2}\right)=500$ Torr), the central $\mathrm{CO}_{2}$ response slope was reduced to about one-fifth of normal, and when the isolated $\mathrm{CB}$ was stimulated $\left(\mathrm{CB} \mathrm{PO}_{2}=40\right.$ Torr, $\mathrm{CB} \mathrm{PCO}_{2}=40$ Torr) the central $\mathrm{CO}_{2}$ response slope increased two-fold on average. a) The effects on the tidal volume $(V \mathrm{~T})$ /inspiratory time (tI) response slope indicate changes in the neural "drive" to breathe and reflect coincident changes in the rate of rise of the diaphragm electromyogram. b) Effects of CB inhibition/ stimulation on the minute ventilation $\left(V^{\prime} \mathrm{E}\right)$ response slope reflect changes in both respiratory frequency and $V$ T. $P \mathrm{aCO}_{2}$ : arterial $\mathrm{CO}_{2}$ tension. Reproduced from [21] with permission from the publisher. c) Schematic of central/peripheral chemoreceptor interdependence. Both the traditional concept supporting only separate chemoreceptor functions (solid lines) and the newer concept of interdependent chemoreceptor function (dashed lines) are shown. NTS: nucleus tractus solitarius; RTN: retrotrapezoid nucleus; CPG: central pattern generator. See panels a), b) and the main text for explanation and references to original research supporting this schematic.

and central respiratory drive [22-24]. Accordingly, when carotid bodies are bilaterally denervated (CBX) in several species, including humans, not only is the hypoxic ventilatory response eliminated (as expected) but in addition, the central hyperoxic $\mathrm{CO}_{2}$ response is also markedly depressed $[25,26]$. These findings are clearly inconsistent with the common presumption that hyperoxic $\mathrm{CO}_{2}$ rebreathing tests selectively test central chemoresponsiveness, per se [27, 28]. Even during normoxic, i.e. air, breathing conditions, denervation of the carotid bodies or inhibition of the isolated, perfused intact carotid bodies [29, 30] results in substantial $25-35 \%$ reductions in alveolar ventilation $\left(V^{\prime} \mathrm{A}\right)$ and $\mathrm{CO}_{2}$ retention in the order of $+5-13 \mathrm{mmHg}$ of arterial $\mathrm{CO}_{2}$ tension $\left(\mathrm{PaCO}_{2}\right)$ that persists for days and often weeks following $\mathrm{CBX}$. We believe this substantial contribution of the carotid body to eupnoeic breathing represents not only a contribution of tonic activity from the carotid bodies to medullary rhythm generating neurons but also the powerful interdependent effects of chemoreceptor input on $\mathrm{RTN} \mathrm{CO}_{2}$-responsive neurons. The central projections of the carotid chemoreceptors to the hypothalamus and specifically to the paraventricular nucleus (PVN) may also be of significance, as shown by the depressed sympathetic and phrenic nerve responses to acute carotid body stimulation achieved by blocking or lesioning neurons in these regions [31].

We can no longer view either the peripheral or central carotid chemoreceptors as "stand-alone" receptors responding only to changes in their immediate environment (fig. 2c). Further, the carotid bodies are not just reflex $\mathrm{O}_{2}$ sensors; rather they appear to provide a nonspecific tonic afferent input that sensitises respiratory pattern generating medullary neurons through multiple central nervous system (CNS) pathways. 
Plasticity/after-effects of sustained chemoreceptor activation

Substantial evidence has accumulated to demonstrate that the ventilatory control system is highly plastic in response to chemoreceptor stimuli. For example, with hypoxia-induced chemoreceptor stimulation three types of post stimulus after-effects and/or plasticity have been observed. First, an acute short-term potentiation occurs as manifested in a slowly declining hyperpnoea persistent for several seconds following withdrawal of carotid body simulation [32], a centrally mediated output that provides a stabilising effect on breathing pattern following transient ventilatory overshoots, especially in sleep [33]. Secondly, a timedependent hyperventilation and increased sympathetic nerve activity occurs over hours and days in the face of sustained hypoxic exposure. This is mediated primarily by increasing carotid sinus nerve output from the carotid body, a chemosensitisation that begins within a few hours of hypoxic exposure [34], and which coincides with increased protein expression and proliferation of $\mathrm{O}_{2}$ sensory glomus cells of the carotid body [35]. Thirdly, upon reversal of the sustained hypoxic stimulus via acute normoxia or even hyperoxia, hyperventilation and the increased sympathetic nerve activity continue, declining only very slowly over several days [36, 37].

In order to explain the persistent hyperventilation and excessive sympathoexcitation following removal of the hypoxic stimulus, some type of ongoing "central" stimulating effect resulting from the prolonged chemoreceptor input is required. Accordingly, central sensitisation of phrenic nerve activity in response to augmented carotid sinus nerve input has also been shown to occur during prolonged hypoxic exposure [38] and this might be explained, at least in part, by sensitisation of central chemoreceptors by heightened carotid body input (fig. 2). In addition, acute CNS hypoxia, per se, especially in the presence of normal tonic input from intact (but isolated) carotid chemoreceptors, causes a tachypnoeic hyperventilation and increased sympathetic nerve activity in unanaesthetised canines and goats [39-41]. This effect probably reflects the balance struck between hypoxia-induced inhibition versus excitation of different groups of medullary and hypothalamic neurons [42]. Sensitivity of these CNS hypoxia-sensitive neurons appears to be enhanced after a few days of hypoxic exposure [43].

\section{Plasticity/after-effects of intermittent hypoxia}

Following even very brief periods of intermittent hypoxia interspersed with normoxia, hyperventilation and increased sympathetic activity are sustained over an hour or more, i.e. so called long-term facilitation [44]. Several mechanisms appear to contribute to the sustained activity following removal of the chemoreceptor stimulus. First, with brief intermittent hypoxia carotid sinus nerve activity remained elevated upon return to normoxia; no morphological changes at the level of the carotid body were apparent. Increased reactive oxygen species and inflammatory cytokines have been implicated in sustained carotid body sensitisation [45]. Increased numbers of carotid body AT1 receptors have also been shown to result from prolonged intermittent hypoxia and to occur in animal models of CHF [46]. In turn, the carotid body sensitisation in CHF models has been attributed to reduced cardiac output and reduced carotid chemoreceptor blood flow (i.e. "stagnant" hypoxia) [13]. Secondly, central adaptive responses also occur following intermittent hypoxia as seen in the persistent elevation of tonic hyperactivity of neurons at the level of the PVN [47] and the rostral ventrolateral medulla [48]. This after-effect phenomenon in the CNS probably contributes significantly to the daytime elevation of sympathetic activity and the hypertension observed during the daytime in patients with OSA and nocturnal intermittent hypoxaemia [49].

Given these recent insights into the mechanisms underlying these types of enhanced chemosensitivity and their after-effects on ventilation and sympathetic activity, further studies have used pharmacological means to attenuate this plasticity. Thus, anti-inflammatory medications [50], blockade of increased reactive oxygen species [51] and prevention of upregulation of angiotensin receptors [52] will all attenuate intermittent hypoxia or low blood flow effects on chemosensitivity. Furthermore, increasing cardiac output via habitual physical training will also attenuate increased chemoreceptor sensitivity in CHF animal models [53]. These approaches all offer as yet untried treatments for chemo-hypersensitivity and its sequelae associated with OSA and autonomic imbalances in humans.

Finally, the after-effects or long-term facilitation of both phrenic and hypoglossal nerve activity elicited by even a few sessions of intermittent hypoxia (for example, eight 2-min intervals of $8 \%$ inspiratory oxygen fraction daily for 10 days) resulted in increased serotonin, immunoreactive brain-derived neurotrophic factor and endothelial growth factor at the level of the phrenic motor neurons $[54,55]$. This type of moderate, brief intermittent hypoxia also upregulated growth and trophic factors in nonrespiratory motor neurons, suggesting that this type of adaptation to intermittent hypoxia represents a general feature of motor systems $[54,55]$. It is important to note that this moderate, short-lived type of intermittent hypoxia, unlike the persistent cyclical and long-lived nature of the intermittent hypoxia associated with severe sleep apnoea, probably has little, if any, persistent daytime effects on chemosensitivity or negative consequences for the cardiovascular system. Accordingly, some investigators are recommending intermittent hypoxia for promoting synaptic plasticity and spontaneous ventilation following selected types of spinal cord injury [56]. 


\section{Exercise hyperpnoea in health and disease}

In healthy humans of all ages, the ventilatory response to exercise of up to 10-20-fold greater than resting levels is achieved with remarkable precision and efficiency in terms of $\mathrm{CO}_{2}, \mathrm{O}_{2}$ and $\mathrm{pH}$ regulation of arterial blood and economy of effort on the part of the respiratory muscles. The key primary drivers of this nearisocapnic hyperpnoea, which is so tightly and mysteriously linked to respiratory $\mathrm{CO}_{2}$ exchange, has been narrowed to a central command, feed-forward stimulus with parallel recruitment of both locomotor and respiratory muscles and a feedback stimulus involving thinly myelinated afferents from contracting locomotor muscles [57]. There is strong evidence linking ventilation to increases and decreases in $\mathrm{CO}_{2}$ flow to the lung (perfusion $\left(\mathrm{Q}^{\prime}\right) \times$ content of $\mathrm{CO}_{2}$ in mixed venous blood) as achieved via diet-induced changes in the respiratory exchange ratio and sinusoidal work rates in humans or via experimental manipulation of venous return to the lung in animal models; for a summary see [57-59]. Although the exact nature of this stimulus and its site(s) of action (presumably in the lung or pulmonary vasculature) remain unknown, we believe the evidence points strongly to an important modulary role for $\mathrm{CO}_{2}$ flow during exercise (see the Healthy ageing section) and especially under resting conditions. For example, note the marked similarity in resting values of arterial (and alveolar) $\mathrm{CO}_{2}$ tension among and within healthy humans of markedly different body mass and tissue $\mathrm{CO}_{2}$ production, which is only achievable via regulation of $V^{\prime} \mathrm{A}$ in precise proportion to $\mathrm{CO}_{2}$ production $\left(V^{\prime} \mathrm{CO}_{2}\right)\left(\mathrm{PaCO}_{2}=V^{\prime} \mathrm{CO}_{2} / V^{\prime} \mathrm{A} \cdot \mathrm{K}\right.$, where $\left.\mathrm{K}=863\right)$. Attempts have been made to implicate the carotid chemoreceptors in this presumed $V^{\prime} \mathrm{CO}_{2}$ effect during exercise; however, several denervation studies have shown that chemoreceptors are not required for the isocapnia hyperpnoea normally achieved in moderate intensity steady-state exercise [57]. However, it is only recently that new insights have been gained into these mechanisms in humans, with implications for the regulation of exercise hyperpnoea in health, COPD and CHF.

\section{Central command}

In the past decade, several lines of evidence have demonstrated the importance of feed-forward central command to exercise hyperpnoea in humans, as originally hypothesised by KROGH and LiNDHARD [60] over a century ago, based on their observation of anticipatory hyperventilation prior to exercise and the immediate increase in ventilation at exercise onset. First, hyperventilation and cardiovascular responses were shown to occur in the hypnotised human at rest in response to "suggested exercise" [61, 62]. This observation extended older ones, which showed that the increased drive to recruit motor units of locomotor muscles during exercise, as triggered by either weakening of the rhythmically contracting muscles via partial curarisation [63] or epidural lidocaine [64, 65], or inhibiting central motor command via tendon vibration [66], was accompanied by increased heart rate and ventilatory responses to a given level of exercise.

Where in the CNS does the central command originate? Animal studies using electrical or pharmacological simulation of subthalamic and mesencephalic locomotor regions have triggered cardiovascular and ventilatory responses in parallel with locomotion, even in the absence of muscle contraction (i.e. fictive locomotion) [67]. In addition, these regions were shown to be activated in intact exercising animals [68]. However, recent human studies clearly point to the motor cortex and midbrain as key sites of central command. First, electrical or magnetic transcranial stimulation [69], deep brain stimulation [70] and stimulation of the primary cortex [71] all elicited diaphragmatic contractions. Secondly, positron emission tomography imaging in the "suggested" exercise paradigm mentioned above revealed increased blood flow to the motor control regions of the cortex and cerebellum [72, 73]. Most recently, the use of deep brain stimulating electrodes, with recording of field potentials, in human neurosurgical patients has been used to specifically identify the periaqueductal grey (PAG) and the subthalamic nucleus (STN) as major sites of central command of cardiorespiratory responses to stress $[72,74,75]$. The PAG receives inputs from prefrontal cortex, hypothalamus and nociceptive pathways, and has outputs to the brainstem medullary cardiorespiratory control areas. Stimulation of muscle afferent inputs in humans also elicited excitation of PAG neuronal activity [75]. PATERSON [76] propose that the PAG area is a key "command centre" of functional connectivity to higher centres and to the STN as well as receiving sensory input from the periphery. These findings have also promoted the concept that the essential nature of the control system for exercise hyperpnoea resides in the central command centres. However, as summarised, below this regulation also appears to require feedback.

\section{Muscle afferent feedback}

When studied in isolation using direct stimulation of muscle in resting humans, substantial evidence exists for thinly myelinated afferents, responding to the mechanical distortions of muscle contraction and/or metabolite accumulation, in the regulation of exercise hyperpnoea. Their sensory pathway ascends via the dorsal horn of the spinal cord to the nucleus of the solitary tract, and to cardiorespiratory neurons of the ventral lateral medulla. What is in doubt is whether these afferents play a significant obligatory role in 
exercise hyperpnoea in the normally exercising human, i.e. when central command and other mechanisms sensitive to respiratory $\mathrm{CO}_{2}$ exchange are also operative. A straightforward approach to determining whether this feedback mechanism is "essential" to the normal hyperpnoea is to block it during steady-state, rhythmic exercise, i.e. when all potential competing stimuli are present. This has been accomplished several times in humans with epidural lidocaine injection and provided negative evidence in all cases, i.e. showing no effect or even an increase in the ventilatory or heart rate response to exercise in the presence of epidural blockade with only a small reduction in blood pressure $[57,64,77]$. However, this approach has been shown to block efferents as well as afferents, causing limb muscle weakness. Thus, as with the curare experiments [63], as mentioned above, this intervention would probably elicit a compensatory response from central command to recruit more motor units in order to maintain force output with corresponding increases in cardiorespiratory responses. Another approach to blocking these afferents, but without affecting the efferent pathway, is to take advantage of their sensitivity to $\mu$-opioids [78]. Accordingly, we used intrathecal administration of fentanyl at the lumbar level as a partial blockade of muscle afferents and demonstrated that this drug did not influence leg strength, nor did it have cardioventilatory effects at rest while breathing room air or $\mathrm{CO}_{2}$ or during rhythmic arm exercise [79]. However, this blockade did cause substantial hypoventilation and $\mathrm{CO}_{2}$ retention as well as significant reductions in blood pressure and heart rate in healthy subjects during rhythmic leg cycling exercise (fig. 3). Similar cardiorespiratory effects of fentanyl were also observed in constant load and time trial cycling exercise [80,81]. We caution that these data do not mean that feedback chemoreception, secondary to the sustained $\mathrm{CO}_{2}$ retention of 4-8 $\mathrm{mmHg} \mathrm{PaCO}_{2}$ observed with afferent blockade, is ineffective. On the contrary, when the ventilatory equivalent of the heightened chemoreceptor activity secondary to the fentanyl-induced $\mathrm{CO}_{2}$ retention was accounted for, it was estimated that the total effect of the fentanyl block approached $40-50 \%$ of the total hyperpnoea during mild and moderate steady-state exercise [58].

It is especially surprising that muscle afferent blockade affected cardioventilatory responses even under conditions of mild-to-moderate exercise intensity where $\mathrm{O}_{2}$ supply to contracting muscle met $\mathrm{O}_{2}$ demand. Such findings are consistent with newer concepts which point to muscle "metaboreceptor" activation in response to venous distention [82], a mechanism which is especially appealing because the proposed stimulus to venous distension, i.e. increased muscle blood flow, is a major determinant of respiratory $\mathrm{CO}_{2}$ exchange and by regulating breathing is participating in its own control. Finally, we need to emphasise that we cannot distinguish whether this substantial contribution of muscle afferents to the cardiorespiratory response found with opioid agonist infusion is secondary to the blockade of the supraspinal pathway from the dorsal horn via the nucleus tractus solitarius to the medullary rhythm generator neurons, and/or whether we have interfered with the interactive effects of ascending afferents on the integrative function of the cortical "central command" centres (see earlier). What seems clear from the blockade data (fig. 3) is that the concept of a purely central, adaptive feed-forward control of the cardioventilatory response to exercise is not tenable. Rather, muscle afferent feedback provides critical information deciding both cardiorespiratory responses as well as locomotor muscle effort or so-called "central fatigue" [80, 81, 83].

\section{Healthy ageing}

The major change affecting exercise hyperpnoea and its limitations with healthy ageing are the marked reductions in lung elastic recoil leading to airway narrowing/closure at high lung volumes, a reduced maximum expiratory flow-volume loop, maldistribution of ventilation and increased dead space ventilation [84-86]. These changes have no discernable effect on resting eupnoeic ventilation or $\mathrm{PaCO}_{2}$ but during exercise there are two major consequences. First, expiratory flow limitation occurs at a level of hyperpnoea that would not elicit these limitations in the younger adult and this in turn will cause hyperinflation, increased work of breathing and dyspnoea. Secondly, even though the dead space volume (VD)/tidal volume $(V \mathrm{~T})$ ratio is increased with age, $\mathrm{PaCO}_{2}$ is maintained near resting normocapnic levels throughout moderate exercise intensities because the elderly subject increases total minute ventilation ( $V^{\prime} \mathrm{E}$ ) (and $V^{\prime} \mathrm{E} / V^{\prime} \mathrm{CO}_{2}$ ) above that in the young, so as to maintain a $V^{\prime} \mathrm{A} / V^{\prime} \mathrm{CO}_{2}$ ratio comparable to that in the young adult (fig. 4). As discussed earlier, we do not know exactly how respiratory $\mathrm{CO}_{2}$ exchange is sensed to promote this precise regulation of $V^{\prime}$ A relative to $V^{\prime} \mathrm{CO}_{2}$, however, these types of evidence confirm the importance of this humoral mechanism at least as a "fine tuner" of the hyperpnoeic response [58, 59]. By contrast, this augmented (total) ventilatory response combined with the age-diminished maximum flow-volume envelope results in flow limitation and a greater work of breathing at any given $V^{\prime} \mathrm{E}$ in the exercising elder [86].

\section{Chronic obstructive pulmonary disease}

COPD represents an extreme example of a highly compliant lung and a compromised expiratory flowvolume loop which precipitates expiratory flow limitation with only modest increases in flow rate above resting levels. The ensuing progressive hyperinflation with mild-to-moderate exercise intensities appears as the major contributor to dyspnoea and to exercise limitation [87]. Three approaches to reducing the 

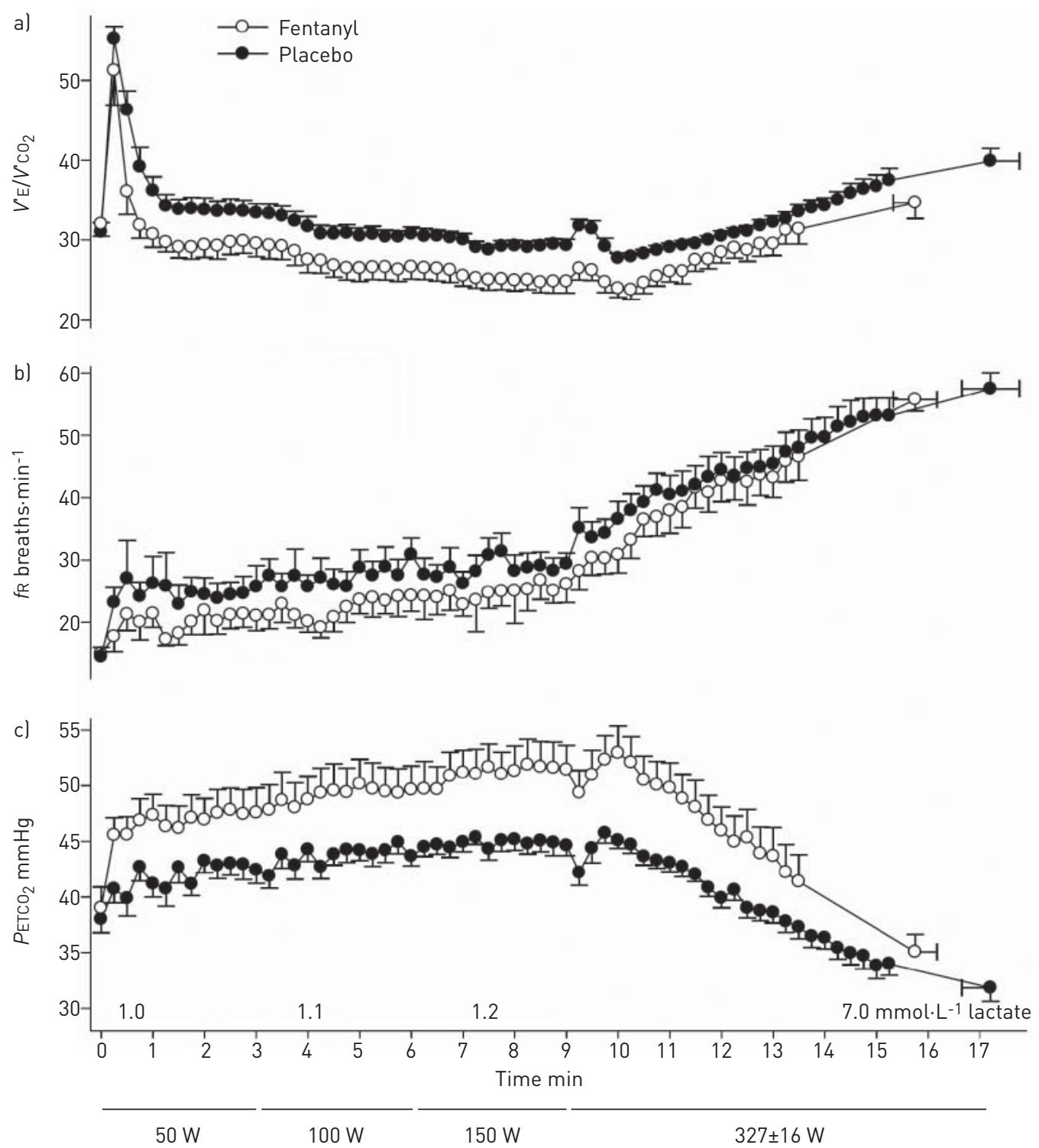

FIGURE 3 a) Reduced steady-state ventilation (minute ventilation $\left(V^{\prime} \mathrm{E}\right) / \mathrm{CO}_{2}$ production $\left(V^{\prime} \mathrm{CO}_{2}\right)$ ) and b) respiratory frequency $(f \mathrm{R})$, and $\mathrm{c}$ ) the resultant $\mathrm{CO}_{2}$ retention (end-tidal $\mathrm{CO}_{2}$ tension $\left(\mathrm{PETCO}_{2}\right)$ ), resulting from type III-IV muscle afferent blockade via intrathecal fentanyl in healthy humans during mild to heavy exercise intensities. Note the persistence of the hypoventilatory response over time in the presence of type III-IV limb muscle afferent blockade, especially during mild and moderate intensity exercise, despite the presence of increased $\mathrm{CO}_{2}$-induced chemoreceptor stimulation. Plasma lactate levels were within $0.5 \mathrm{mmol} \cdot \mathrm{L}^{-1}$ of resting values $\left(0.9 \pm 0.1 \mathrm{mmol} \cdot \mathrm{L}^{-1}\right)$ during $50-150 \mathrm{~W}$ exercise and rose to seven-fold greater than resting values during exercise at $325 \mathrm{~W}$ in both the placebo and fentanyl trials. Reproduced from [79] with permission from the publisher.

expiratory flow limitation have resulted in improved exercise performance and decreased limb fatigue. First, inhalation of low density $\mathrm{He} / \mathrm{O}_{2}$ mixtures expands the maximum flow-volume envelope in most patients thereby reducing the exercise-induced expiratory flow limitation during tidal breathing and also reducing the rate of development of limb fatigue during exercise [88]. Secondly, supplemental inspired $\mathrm{O}_{2}$ reduced chemoreceptor drive and exercise $V^{\prime} \mathrm{E}$, slowed the rate of development of limb muscle fatigue [88] and improved exercise performance [88, 89]. Thirdly, intrathecal fentanyl was used (fig. 5) to reduce muscle afferent input in COPD patients, resulting in reduced breathing frequency, which in turn reduced dead space minute ventilation and total ventilation (but not $V^{\prime} \mathrm{A}$ ), flow limitation and hyperinflation [90]. So, as in health (fig. 3), muscle afferent input in exercising COPD patients contributes significantly to exercise hyperpnoea but with a negative, rather than positive, influence on exercise performance [58]. Given the markedly diminished aerobic capacity and reduced fatigue resistance [88] of limb locomotor muscles in the 

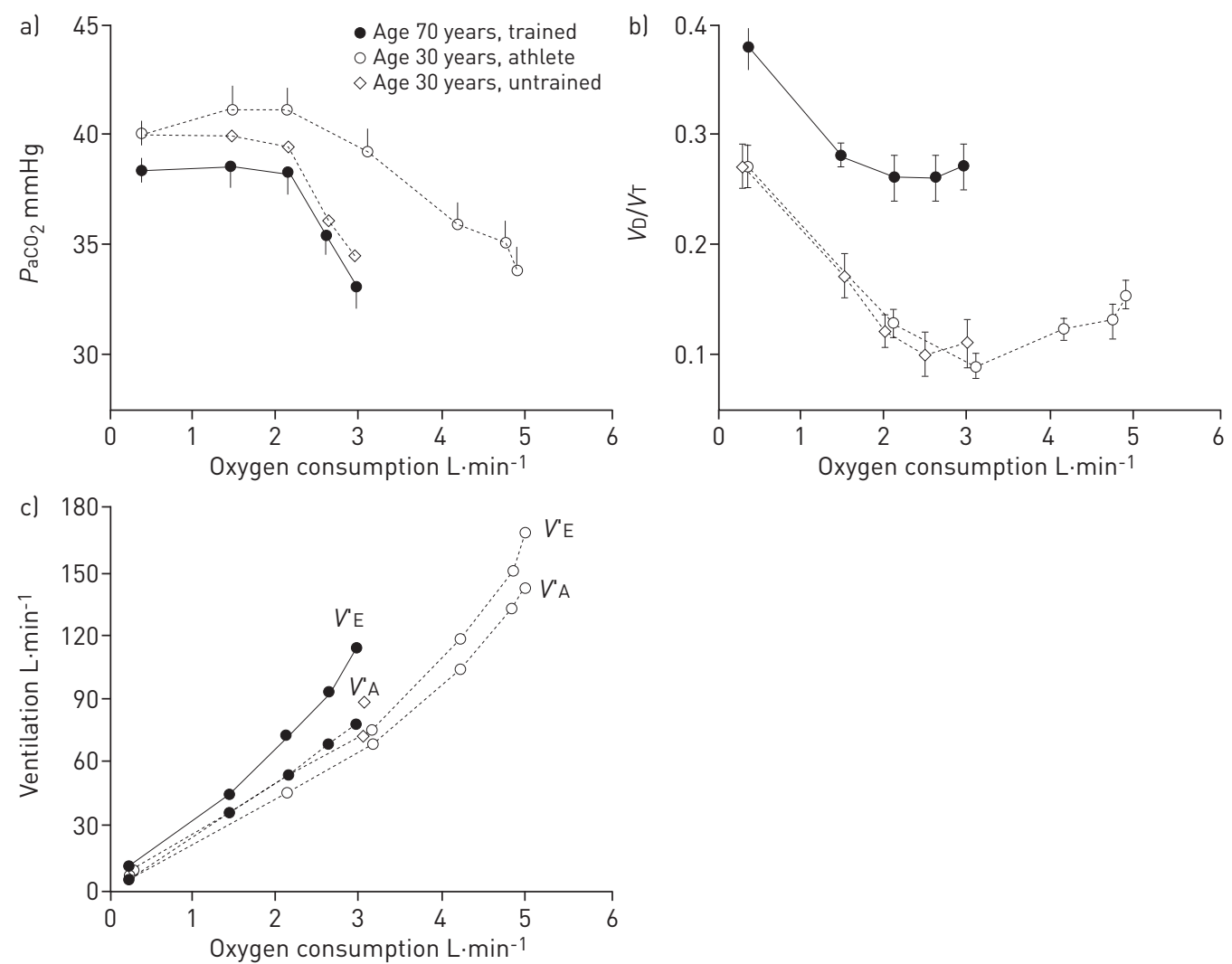

FIGURE 4 Steady-state ventilatory response to treadmill walking in young and elderly healthy subjects. a) Arterial $\mathrm{CO}_{2}$ tension $\left(\mathrm{PaCO}_{2}\right)$ is determined by the relationship of alveolar ventilation $\left(V^{\prime} \mathrm{A}\right)$ to $\mathrm{CO}_{2}$ production $\left(V^{\prime} \mathrm{CO}_{2}\right)$ so that $\mathrm{PaCO}_{2}=\left(V^{\prime} \mathrm{CO}_{2} / V^{\prime} \mathrm{E}-V^{\prime} \mathrm{D}\right) \times \mathrm{K}$ where $V^{\prime} \mathrm{E}$ is total minute ventilation, $V^{\prime} \mathrm{D}$ is dead space minute ventilation and $\mathrm{K}$ is a constant [58]. b) Note in the elderly that their dead space ventilation (dead space volume (VD)/tidal volume $(V T)$ ) is greater than in younger subjects at rest and exercise. c) The older subjects adjust their total $V^{\prime} \mathrm{E} / V^{\prime} \mathrm{CO}_{2}$ so it is higher than in the young during mild-to-moderate intensity exercise resulting in similar $V^{\prime} \mathrm{A} / V^{\prime} \mathrm{CO}_{2}$ ratio and isocapnic hyperpnoea. Data from [85].

sedentary COPD patient $[91,92]$, specific resistance training of the legs [93] might result in reduced stimuli to muscle metaboreflexes and, therefore, less tachypnoea and hyperpnoeic response to exercise.

\section{Congestive heart failure}

CHF patients commonly respond to exercise with tachypnoeic hyperventilation and even occasionally oscillatory breathing over time, the severity of which is prognostic of morbidity and mortality in CHF
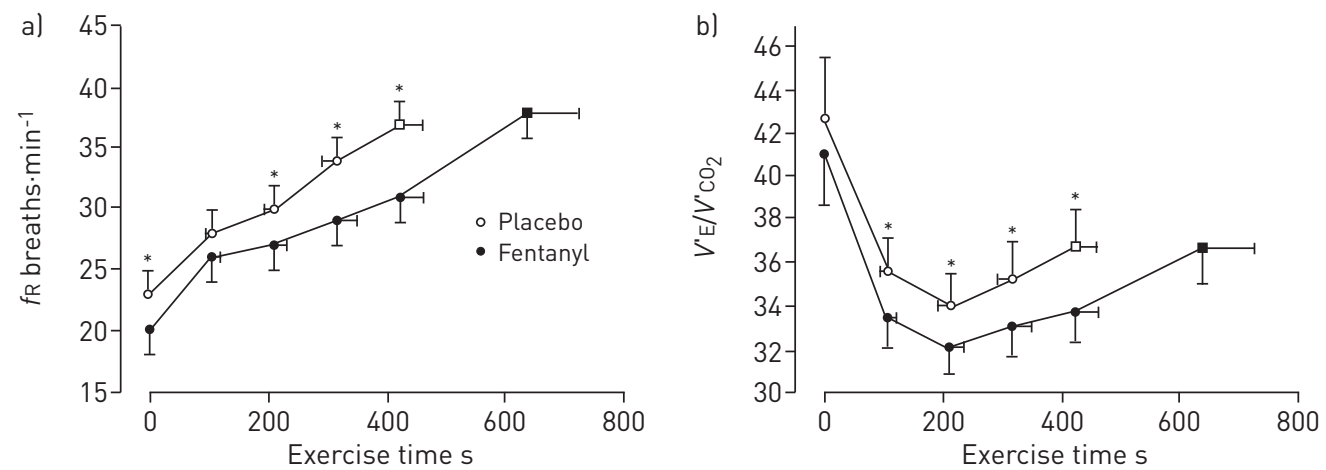

FIGURE 5 Effects of intrathecal fentanyl blockade on a) respiratory frequency $(f \mathrm{R})$ and b) minute ventilation $\left(V^{\prime} \mathrm{E}\right) / \mathrm{CO}_{2}$ production $\left(V^{\prime} \mathrm{CO}_{2}\right)$ ratio in chronic obstructive pulmonary disease patients cycling at $80 \mathrm{~W}$ (80\% of maximum). Fentanyl block resulted in a reduced $f \mathrm{R}$ and $V^{\prime} \mathrm{E} / V^{\prime} \mathrm{CO}_{2}$ which persisted throughout the exercise. Dead space volume/tidal volume ratio during exercise was also reduced as $f R$ fell with fentanyl (data not shown). Dyspnoeic sensations were reduced and exercise time prolonged as $V^{\prime} \mathrm{E}$ and expiratory flow limitation were reduced with fentanyl blockade. ${ }^{\star}: \mathrm{p}<0.05$ between conditions. Reproduced from [90] with permission from the publisher. 
patients $[94,95]$. Deadspace ventilation and $V^{\prime} \mathrm{E} / V^{\prime} \mathrm{CO}_{2}$ are high, owing primarily to the increased breathing frequency, but so is $V^{\prime} \mathrm{A} / V^{\prime} \mathrm{CO}_{2}$; thus, arterial hypocapnia is common [96]. There are several potential reasons for the hyperventilatory response. First, carotid chemoreceptors are substantially hypersensitised in $\mathrm{CHF}$, owing to the chronic "stagnant hypoxia" at the level of carotid body created by the low cardiac output, low blood flow and reduced shear stress [13]. This chemo-hypersensitisation will also increase control system loop gain (see the section on OSA) and contribute to the unstable, oscillatory ventilation sometimes observed during exercise [97]. Secondly, muscle mechanoreceptors are also hypersensitised in CHF in combination with a depressed muscle metaboreceptor sensitivity [98, 99]. Accordingly, intrathecal fentanyl-induced blockade of muscle afferents in human $\mathrm{CHF}$ patients resulted in substantial hypoventilation and $\mathrm{CO}_{2}$ retention over a wide range of exercise intensities as compared with agematched controls [100]. Thirdly, high pulmonary vascular pressures are common in CHF, especially during exercise and in the presence of pulmonary oedema; this would precipitate pulmonary $\mathrm{C}$ fibre stimulation and a tachypnoeic ventilatory response and would also be expected to contribute to unstable, oscillatory ventilation $[95,101]$.

These hyperventilatory responses as well as the underlying hypersensitivity of muscle afferents and chemoreceptors in CHF contribute importantly to exercise performance limitation. This is primarily because of the augmented intrathoracic pressures and increased work of breathing and accompanying dyspnoea as well as high sympathetic vasoconstrictor outflow effects on limb perfusion. Thus, when pressure support mechanical ventilation was used to reduce respiratory muscle work in CHF patients, ratings of limb discomfort were reduced and exercise performance improved [102]. Further, pressure support elicited substantial increases in limb muscle blood flow and muscle oxygenation [103, 104], in both CHF patients and an animal model [105], due to both an increase in stroke volume and cardiac output in combination with a greater local vasodilation of locomotor muscle vasculature. This dual effect, i.e. increased cardiac output and limb vascular conductance during exercise with pressure support, was attributed to: 1) a mechanical effect of reduced intrathoracic pressure on the left ventricle in the highly afterload-dependent CHF patient, an effect which is in the opposite direction to the decreased stroke volume observed with positive pressure support during exercise in health $[105,106]$; and 2) a reduced reflex feedback effect from respiratory muscle metaboreceptors [105]. Similarly, transient inhibition of hypersensitised carotid chemoreceptors in CHF animal models also reduced locomotor muscle vascular resistance and increased limb blood flow both at rest and during exercise [107].

Chronic exercise training $[108,109]$ as well as specific respiratory muscle training $[110,111]$ in CHF animal models and in human patients reduces the hypersensitivity of the carotid chemoreceptors, limb muscle mechanoreceptors and the respiratory muscle metaboreflex. These "desensitising" effects on multiple feedback regulators result in a reduced work of breathing and reduced sympathetic vasoconstriction, thereby improving $\mathrm{O}_{2}$ transport to contracting locomotor muscles and exercise performance.

\section{OSA and the ventilatory control system}

Significant amounts of sleep apnoea and sleep disordered breathing exist in the general population, with obesity, male sex, age and craniofacial structure as major risk factors [49]. Severe cases (apnoea-hypopnoea index (AHI)/oxyhaemoglobin $\left(\mathrm{HbO}_{2}\right)$ desaturations $>20-30$ events $\left.\cdot \mathrm{h}^{-1}\right)$ commonly lead to high chemosensitivity, elevated sympathetic vasoconstrictor activity and endothelial dysfunction, all of which elicit both nocturnal and daytime systemic and often pulmonary hypertension [49]. A form of daytime hypoventilation and $\mathrm{CO}_{2}$ retention in the obese is also tightly linked, perhaps in part via chemoreceptor "resetting", to carryover effects from nocturnal hypoventilation and $\mathrm{CO}_{2}$ retention during sleep and is often effectively eliminated via the use of nasal positive pressure ventilation to correct the nocturnal hypoventilation [112]. In many CHF patients and sojourners to high altitude, the ventilatory control system and enhanced chemosensitivity clearly play a major role in the pathogenesis of "central" or mixed (obstructive plus central) type of repetitive apnoeas [113]. But what role might these control mechanisms play in the more prevalent condition of cyclical OSA? Certainly the popular view that OSA is a problem of an anatomically compromised upper airway has merit, but accumulating evidence now recognises that repetitive airway obstructions in sleep are also often a function of other important characteristics of the ventilatory control system $[40,114,115]$.

\section{Anatomical/functional links in OSA}

First, we know that central respiratory motor output recruits first the hypoglossal, then (milliseconds later) the phrenic motor neurons serving the upper airway dilators and respiratory pump musculature, respectively $[116,117]$. Secondly, the fundamental effects of the loss of "wakefulness" include both the withdrawal of tonic input to the upper airway dilator muscles, thereby increasing airway compliance and collapsibility, plus an unmasking of a critical dependence of ventilatory control and its stability on 
chemoreceptor and mechanoreceptor feedback. Thirdly, in subjects with moderately collapsible airways there is a tight link between $\mathrm{CO}_{2}$-induced central ventilatory instability and airway calibre. Therefore, inducing central output instability by administering brief hypoxic episodes in snoring subjects with mildly collapsible airways precipitated airway closure at the nadir of the oscillating drive [118, 119]; conversely, preventing oscillations in central respiratory motor output by preventing transient hypocapnia via dead space rebreathing, also prevented airway obstructions, at least in those subjects with a relatively high chemosensitivity and sensitive apnoeic threshold [120]. Finally, the passive collapsibility of the upper airway, by itself, in sleeping humans accounts for only a relatively small portion of the variability in AHI in OSA [121, 122]. Alternatively, recent studies of substantial numbers of OSA patients with moderate-tosevere OSA reveal that more than $80 \%$ have a highly collapsible airway, but $30-50 \%$ also showed key characteristics of central instability including high control system "loop gain", sensitive arousal thresholds and/or sluggish responsiveness of upper airway dilator muscles to chemoreceptor stimuli $[114,120,123,124]$. These characteristics are sometimes inherent to the patient, but are also acquired and intensified via the repeated intermittent hypoxaemia, transient arousals and obstructions.

The tendency towards ventilatory instability depends on "loop gain", an engineering term defining the gain of the negative feedback loop which regulates how ventilation responds to transient disturbances in breathing and the accompanying disruption of arterial blood gases. In turn, loop gain is determined by both controller (chemosensitive) and plant gains. Chemosensor gain is defined by the slope of the ventilatory response to hypercapnia and hypocapnia, i.e. $\Delta V^{\prime} \mathrm{E} / \Delta P \mathrm{aCO}_{2}$. Plant gain is determined by the magnitude of the reduction in $\mathrm{PaCO}_{2}$ resulting from a given change in ventilation $\left(\Delta \mathrm{PaCO}_{2} / \Delta V^{\prime} \mathrm{E}\right)$, i.e. the efficiency with which $\mathrm{CO}_{2}$ is eliminated. These concepts and their effects on ventilatory stability and the apnoeic threshold may be more readily appreciated when presented in graphical form (see references [97] and [125]).

\section{OSA pathogenesis}

In figure 6 we suggest two overlapping scenarios for the pathogenesis of cyclical OSA, based on the influences of airway collapsibility, neurochemical influences over pharyngeal dilators and respiratory pump musculature on sleep stage stability. In one scenario, a patient with a highly collapsible airway often experiences complete airway collapse when the compensatory tonic input to the upper airways are removed with sleep onset. In the other scenario, a patient with a high chemosensitivity plus a mildly collapsible airway is likely to experience airway obstruction during sleep at the nadir of the oscillating central respiratory motor output. In either case, whether the obstruction is repeated and becomes cyclical will depend upon how the patient's respiratory control system responds to the obstruction as outlined in figures 6 and 7. The key ingredients to regaining respiratory stability are the ability to recruit airway muscle dilators and to open the airway effectively to restore airflow prior to arousal, because the transient arousal accentuates the ventilatory overshoot and hypocapnia leading to subsequent hypopnoeas, apnoeas and obstructions. Accordingly, how the chemoreceptor control system and the airway dilator musculature responds to accumulating $\mathrm{CO}_{2}$ and $\mathrm{HbO}_{2}$ desaturation during the apnoea as well as the sensitivity of a patient's arousal threshold and the effectiveness of dilator muscle recruitment will determine whether initial obstructive events are followed by stable breathing, slowly evolving hypopnoeas with occasional arousals or repetitive obstructions [102].

\section{Treatment implications}

Given the critical contributions of a collapsible airway to all types of OSA it is not surprising that continuous positive airway pressure (CPAP) is a highly effective treatment. However, significant numbers of OSA patients are unable to tolerate CPAP or greatly underutilise it [126]. Three types of alternative treatments have shown promise in significantly reducing AHI in selected OSA patients. These include the following: use of supplemental $\mathrm{O}_{2}$ to reduce chemoreceptor gain $[120,125]$ and administration of acetazolamide $[123,127]$ or preventing hypocapnia via selective increments in inspiratory $\mathrm{CO}_{2}$ fraction to reduce plant gain [120]; raising the arousal threshold using sedatives to prevent ventilatory overshoot by helping maintain sleep state during an obstructive apnoeic event until airway dilator muscle recruitment restores patency prior to arousal [128-130]; reducing airway collapsibility via recruitment of airway muscle dilators using small increments in $\mathrm{PaCO}_{2}$ via a deadspace rebreathing system [120]. In addition, combining treatments to reduce loop gain or raise arousal threshold, together with small reductions in airway collapsibility via moderate weight loss or mandibular advancement has also been attempted [131-133].

These new approaches have produced mixed results to date, with the most consistent success in reducing obstructive AHI achieved when the treatment was tailored to an individual patient's specific deficiency; for example, lowering loop gain in the patient with high chemosensitivity or raising arousal threshold in those with high arousability. A challenge in using these approaches for treatment purposes is simplifying our ability to recognise specific risk factors in OSA populations so that therapy can be individualised and 


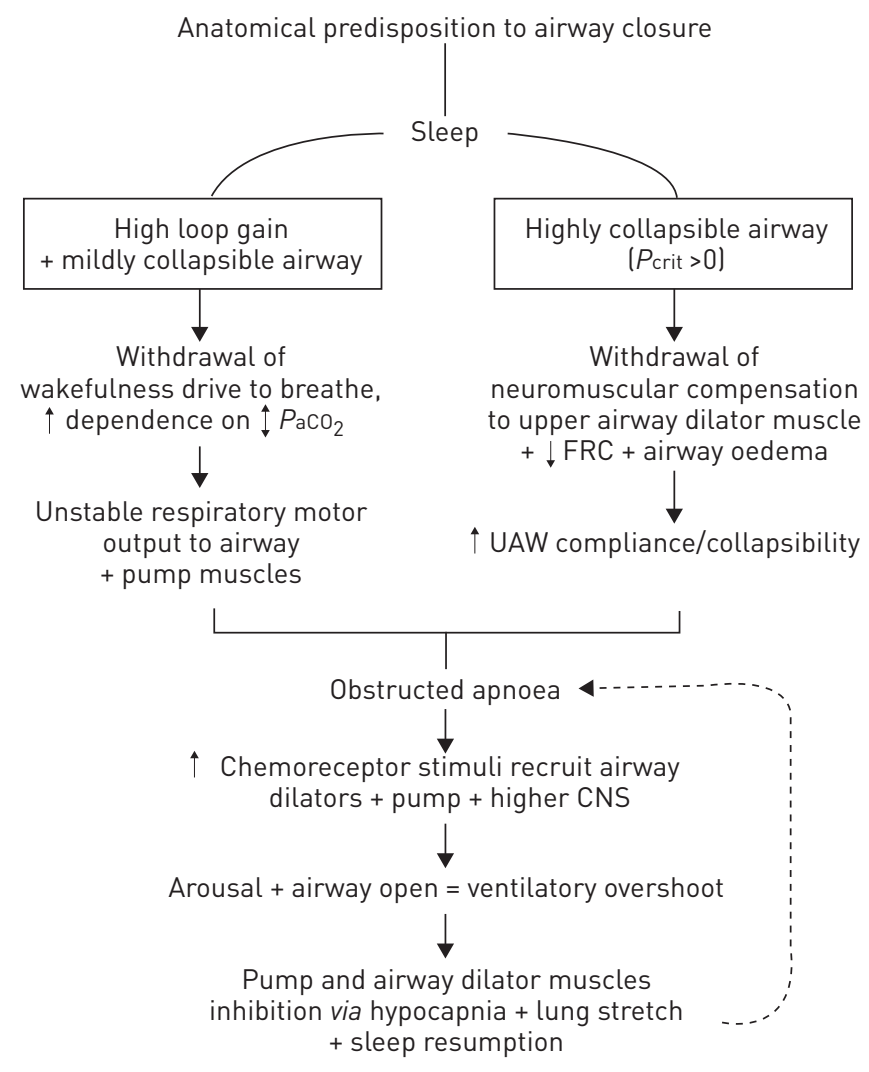

FIGURE 6 Schematic illustrating the interactive effects of airway anatomy with neurochemical control on the magnitude and stability of central respiratory motor output, airway muscle dilator recruitment, and arousability in the pathogenesis of cyclical obstructive sleep apnoea (OSA). Patients with an anatomical predisposition to pharyngeal collapse may experience two types of overlapping scenarios leading to cyclical OSA in sleep. Right: progression initiated by an airway obstruction at sleep onset in a patient with a severely collapsible upper airway; left: progression to airway obstruction (at the nadir of the respiratory cycle) initiated by an unstable central respiratory motor output in a patient with elevated loop gain and a mildly collapsible airway. Bottom: factors that determine the consequences of airway obstruction and accumulating chemoreceptor stimuli during the obstructive apnoeic period on subsequent, post-apnoeic electroencephalogram arousal, ventilation and airway patency, i.e. all of which will dictate whether the apnoeic episodes will become cyclical. These control system characteristics include the chemoresponsiveness of both the upper airway and chest wall pump muscles, and of central nervous system (CNS) arousability to the rising chemoreceptor stimuli (also see the main text and fig. 7). $\mathrm{PaCO}_{2}$ : arterial $\mathrm{CO}_{2}$ tension; Pcrit: critical value of positive end-expiratory pressure; FRC: functional residual capacity; UAW: upper airway. Reproduced from [40] with permission from the publisher.

targeted [40, 114]. Recently, WeLLMAN et al. [134] have proposed a promising screening tool using the routine clinical polysomnogram to characterise these risk factors in individual OSA patients. We also need to continue to explore new agents for reducing loop gain and arousability and especially for effective stimulation of upper airway muscle dilators without invoking confounding side-effects on chemoreceptor gain or sleep state continuity or excessive sympathetic activation.

These principles of individualising therapy for OSA by phenotyping patients have also been recently applied to an exciting, novel treatment for moderate-to-moderately severe OSA that utilises hypoglossal nerve stimulation during inspiration via implanted electrodes triggered by an implanted transducer which senses intrathoracic pressure [135, 136]. This therapy, which recently received Food and Drug Administration approval in the USA, was shown to be safe and highly effective over a 6 month period in substantially reducing AHI in most of a selected group of CPAP-intolerant OSA patients. Importantly, in keeping with the concept of tailoring treatments to individual characteristics, these patients were prescreened to: 1) include only those with a site of upper airway collapse most likely to be prevented by forward movement of the tongue, achieved via hypoglossal nerve stimulation; and 2) to exclude those with a significant prevalence of central and mixed apnoeas [136]. Based on current knowledge of the pathophysiology of OSA, we would predict that the patients included in this latter category would probably have high chemosensitivity and loop gain. These patients might well benefit from a combined therapy of hypoglossal stimulation plus reduced chemoreflex gain, achieved via supplemental $\mathrm{O}_{2}$ or by means of an (as yet undiscovered) pharmacologically induced reversible blockade of hyperchemosensitivity. 


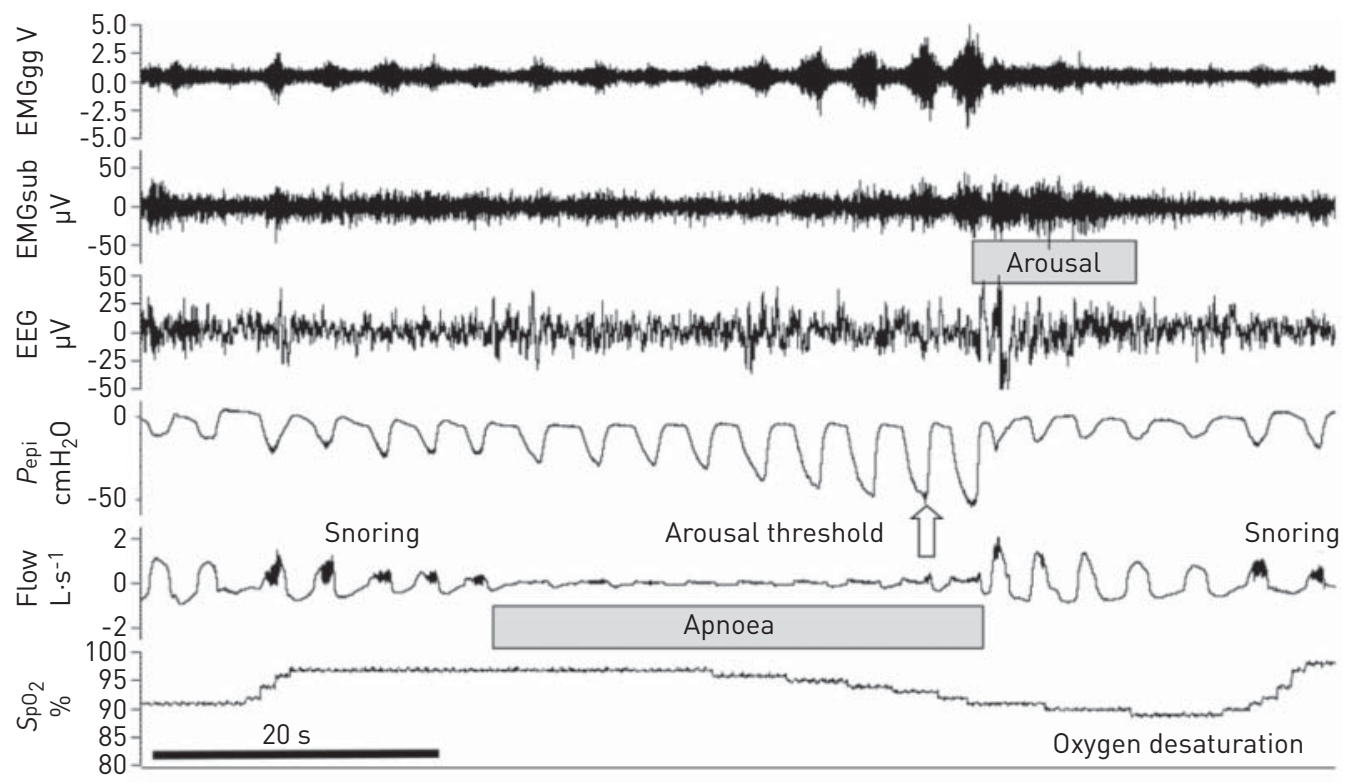

FIGURE 7 Polysomnographic tracing of an obstructed apnoeic event to illustrate the compensatory events occurring during and following the obstruction. The patient had an apnoea-hypopnoea index of 56 events $\cdot \mathrm{h}^{-1}$. The cessation and resumption of flow defines the apnoeic event. Note the progressive increase in inspiratory effort (Pepi) and airway dilator muscle electromyogram (EMG) during the apnoea, the transient arousal coincident with airway opening and ventilatory overshoot at apnoea termination. As the patient returns to sleep, note the gradual reduction in breathing frequency and flow rate, and increased pharyngeal pressure (signifying increased airway resistance) leading to the next obstruction. Evidence of snoring is shown on the flow tracing. Progressive increases in EMGgg activity occurred throughout the obstructive event, although in this instance they were not sufficient to restore flow, which occurred only upon arousal. Pharyngeal pressure serves as a measure of the inspiratory effort made against the obstructed airway, thereby reflecting the magnitude of central respiratory motor output in response to chemoreceptor stimuli accumulated during the obstructed apnoea. Arousal is determined by the pharyngeal pressure achieved through respiratory pump muscle contractions during an airway obstruction at the point of EEG arousal. EMGgg: EMG of the genioglossus muscle (intramuscular); EMGsub: EMG of the submental muscle (surface); EEG: electroencephalogram (C3-A2); Pepi: pressure at the level of the epiglottis; Flow: airflow measured via nasal mask and pneumotachograph; $\mathrm{SpO}_{2}$ : arterial oxygen saturation measured via pulse oximetry at the finger. Reproduced from [114] with permission from the publisher.

\section{Carotid body denervation as "treatment" for autonomic imbalances/OSA?}

Throughout this review, we have emphasised the important contributions of carotid chemoreceptors and their central projections and carotid body hypersensitivity to ventilatory control during exercise and sleep, and to excessive sympathetic nerve activity in such diseases as chronic hypertension, heart failure and OSA. Does it follow that CBX should be considered as a treatment to correct this autonomic imbalance in such diseases as drug-resistant hypertension or CHF, or to prevent (some forms) of sleep apnoea [137, 138]? There is support for carotid body denervation: 1) some older studies of CBX in asthmatic humans showed significant sustained reductions in blood pressure [139]; 2) in the rabbit model of CHF, CBX reduced renal sympathetic nerve activity and blood pressure and prevented periodic breathing [140], and in rodent models of spontaneous hypertension, CBX caused substantial reductions in systemic blood pressure [141]; 3 ) in rodents CBX prevented the development of insulin resistance and hypertension induced via hypercaloric diets [142], substantially increased survival following myocardial infarction [143] and prevented hypertension induced by chronic intermittent hypoxaemia [144]; and d) using an irreversible pharmacological inhibitor of the enzyme responsible for the gaseous transmitter $\mathrm{H}_{2} \mathrm{~S}$ in the carotid body in a rodent model of severe CHF almost completely normalised the heightened carotid chemosensitivity as well as the accompanying breathing instability and sympathoexcitatory state [145]. However, there are concerns, including: 1) whether selective chemo-denervation can be achieved without affecting baroreceptor sensory input or its sensitivity [146]; 2) to what extent will long-term compensation for CBX normalise markedly reduced $\mathrm{CO}_{2}$ chemosensitivity and eupnoeic ventilation in humans [147]; 3) in the absence of carotid chemoreceptors, will patients with airway disease, $V^{\prime} \mathrm{A} / \mathrm{Q}^{\prime}$ maldistribution and high $V D / V \mathrm{~T}$ mount sufficient compensatory hyperpnoea to prevent chronic hypercapnia [147]; and 4) will those denervated patients who develop OSA, with ageing and/or weight gain or upon achieving a post-menopausal state, experience apnoea prolongation and more severe hypoxaemia and its sequelae [40, 120]? Of course, following CBX, any sojourn to even moderately high altitudes will markedly exacerbate the usual level of 
arterial hypoxaemia. Alternatively, we need to determine if therapies that acutely inhibit carotid chemoreceptors or chronically reduce carotid chemoreceptor hypersensitivity present effective, safe and especially reversible alternatives, and in what subpopulation of patients these approaches are likely to be effective. A strong case may also be made for the well documented chemoreceptor desensitising and sympathoinhibitory effects of habitual exercise training, especially interval-type training, in CHF and hypertension [148-151].

\section{Summary}

The major take-home message of our brief review is that recent advances in our basic understanding of ventilatory control, especially those chemoreceptor and extra-chemoreceptor mechanisms controlling breathing and its plasticity during exercise and in sleep, have important implications for understanding the pathophysiology of breathing abnormalities and their consequences in such diseases as COPD, CHF and OSA. A major benefit to these newfound insights is that they are beginning to allow some innovative, meaningful inroads into treatment strategies.

\section{Acknowledgements}

We thank Anthony Jacques (University of Wisconsin-Madison, Madison, WI, USA) for his expert assistance with manuscript and figure preparation.

\section{References}

Feldman JL, Del Negro CA, Gray PA. Understanding the rhythm of breathing: so near, yet so far. Annu Rev Physiol 2013; 75: 423-452.

2 Smith JC, Abdala AP, Borgmann A, et al. Brainstem respiratory networks: building blocks and microcircuits. Trends Neurosci 2013; 36: 152-162.

3 Smith JC, Abdala AP, Koizumi H, et al. Spatial and functional architecture of the mammalian brain stem respiratory network: a hierarchy of three oscillatory mechanisms. J Neurophysiol 2007; 98: 3370-3387.

4 Alheid GF, Milsom WK, McCrimmon DR. Pontine influences on breathing: an overview. Respir Physiol Neurobiol 2004; 143: 105-114.

5 Ono S, Takahashi K, Jinnai $\mathrm{K}$, et al. Loss of catecholaminergic neurons in the medullary reticular formation in myotonic dystrophy. Neurology 1998; 51: 1121-1124.

6 Schwarzacher SW, Rüb U, Deller T. Neuroanatomical characteristics of the human pre-Bötzinger complex and its involvement in neurodegenerative brainstem diseases. Brain 2011; 134: 24-35.

7 Lalley PM, Pilowsky PM, Forster HV, et al. The preBötzinger complex is not essential for the respiratory depression following systemic administration of opioid analgesics. J Physiol 2014; 592: 1163-1166.

8 Montandon G, Horner R. The preBötzinger complex is essential for the respiratory depression following systemic administration of opioid analgesics. J Physiol 2014; 592: 1159-1162.

9 Heymans C, Bouckaert JJ. Les chemo-récepteurs du sinus carotidien [Chemoreceptors of the carotid sinus]. Ergeb Physiol 1939; 41: 28-55.

10 Mitchell RA, Loeschcke $\mathrm{HH}$, Massion $\mathrm{WH}$, et al. Respiratory responses mediated through superficial chemosensitive areas on the medulla. J Appl Physiol 1963; 18: 523-533.

11 Peers C, Wyatt CN, Evans AM. Mechanisms for acute oxygen sensing in the carotid body. Respir Physiol Neurobiol 2010; 174: 292-298.

Prabhakar NR, Semenza GL. Gaseous messengers in oxygen sensing. J Mol Med (Berl) 2012; 90: 265-272.

13 Ding Y, Li YL, Schultz HD. Role of blood flow in carotid body chemoreflex function in heart failure. J Physiol 2011; 589: $245-258$.

14 Kumar P, Bin-Jaliah I. Adequate stimuli of the carotid body: more than an oxygen sensor? Respir Physiol Neurobiol 2007; 157: 12-21.

15 Guyenet PG. Neural structures that mediate sympathoexcitation during hypoxia. Respir Physiol 2000; 121: 147-162. Guyenet PG, Stornetta RL, Bayliss DA. Central respiratory chemoreception. J Comp Neurol 2010; 518: 3883-3906. Nattie E, Li A. Central chemoreceptors: locations and functions. Compr Physiol 2012; 2: 221-254.

Stornetta RL, Moreira TS, Takakura AC, et al. Expression of Phox2b by brainstem neurons involved in chemosensory integration in the adult rat. J Neurosci 2006; 26: 10305-10314.

19 Weese-Mayer DE, Berry-Kravis EM, Ceccherini I, et al. Congenital central hypoventilation syndrome (CCHS) and sudden infant death syndrome (SIDS): kindred disorders of autonomic regulation. Respir Physiol Neurobiol 2008; 164: $38-48$.

20 Barna BF, Takakura AC, Moreira TS. Acute exercise-induced activation of Phox2b-expressing neurons of the retrotrapezoid nucleus in rats may involve the hypothalamus. Neuroscience 2014; 258: 355-363.

21 Blain GM, Smith CA, Henderson KS, et al. Peripheral chemoreceptors determine the respiratory sensitivity of central chemoreceptors to $\mathrm{CO}_{2}$. J Physiol 2010; 588: 2455-2471.

22 Duffin J, Mateika JH. Cross-Talk opposing view: peripheral and central chemoreflexes have additive effects on ventilation in humans. J Physiol 2013; 591: 4351-4353.

23 Teppema LJ, Smith CA. CrossTalk opposing view: peripheral and central chemoreceptors have hyperadditive effects on respiratory motor control. J Physiol 2013; 591: 4359-4361.

24 Wilson RJ, Day TA. CrossTalk opposing view: peripheral and central chemoreceptors have hypoadditive effects on respiratory motor output. J Physiol 2013; 591: 4355-4357.

25 Dahan A, Nieuwenhuijs D, Teppema L. Plasticity of central chemoreceptors: effect of bilateral carotid body resection on central $\mathrm{CO}_{2}$ sensitivity. PLoS Med 2007; 4: e239.

26 Rodman JR, Curran AK, Henderson KS, et al. Carotid body denervation in dogs: eupnea and the ventilatory response to hyperoxic hypercapnia. J Appl Physiol 2001; 91: 328-335. 

$230-243$.

28 Read DJ. A clinical method for assessing the ventilatory response to carbon dioxide. Australas Ann Med 1967; 16: 20-32.

29 Blain GM, Smith CA, Henderson KS, et al. Contribution of the carotid body chemoreceptors to eupneic ventilation in the intact, unanesthetized dog. J Appl Physiol 2009; 106: 1564-1573.

30 Forster HV. Plasticity in the control of breathing following sensory denervation. J Appl Physiol 2003; 94: 784-794.

31 Reddy MK, Patel KP, Schultz HD. Differential role of the paraventricular nucleus of the hypothalamus in modulating the sympathoexcitatory component of peripheral and central chemoreflexes. Am J Physiol Regul Integr Comp Physiol 2005; 289: R789-R797.

32 Eldridge FL. Central neural respiratory stimulatory effect of active respiration. J Appl Physiol 1974; 37: 723-735.

33 Badr MS, Skatrud JB, Dempsey JA. Determinants of poststimulus potentiation in humans during NREM sleep. J Appl Physiol 1992; 73: 1958-1971.

34 Nielsen AM, Bisgard GE, Vidruk EH. Carotid chemoreceptor activity during acute and sustained hypoxia in goats. J Appl Physiol 1988; 65: 1796-1802.

35 Wang ZY, Olson EB Jr, Bjorling DE, et al. Sustained hypoxia-induced proliferation of carotid body type I cells in rats. J Appl Physiol 2008; 104: 803-808.

36 Dempsey JA, Powell FL, Bisgard GE, et al. Role of chemoreception in cardiorespiratory acclimatization to, and deacclimatization from, hypoxia. J Appl Physiol 2014; 116: 858-866.

37 Hansen J, Sander M. Sympathetic neural overactivity in healthy humans after prolonged exposure to hypobaric hypoxia. J Physiol 2003; 546: 921-929.

38 Dwinell MR, Powell FL. Chronic hypoxia enhances the phrenic nerve response to arterial chemoreceptor stimulation in anesthetized rats. J Appl Physiol 1999; 87: 817-823.

39 Curran AK, Rodman JR, Eastwood PR, et al. Ventilatory responses to specific CNS hypoxia in sleeping dogs. J Appl Physiol 2000; 88: 1840-1852.

40 Dempsey JA, Xie A, Patz DS, et al. Physiology in medicine: obstructive sleep apnea pathogenesis and treatmentconsiderations beyond airway anatomy. J Appl Physiol 2014; 116: 3-12.

41 Engwall MJ, Smith CA, Dempsey JA, et al. Ventilatory afterdischarge and central respiratory drive interactions in the awake goat. J Appl Physiol 1994; 76: 416-423.

42 Neubauer JA, Sunderram J. Oxygen-sensing neurons in the central nervous system. J Appl Physiol 2004; 96: 367-374.

43 Nolan PC, Dillon GH, Waldrop TG. Central hypoxic chemoreceptors in the ventrolateral medulla and caudal hypothalamus. Adv Exp Med Biol 1995; 393: 261-266.

44 Mitchell GS, Johnson SM. Neuroplasticity in respiratory motor control. J Appl Physiol 2003; 94: 358-374.

45 Peng YJ, Prabhakar NR. Effect of two paradigms of chronic intermittent hypoxia on carotid body sensory activity. J Appl Physiol 2004; 96: 1236-1242.

46 Marcus NJ, Li YL, Bird CE, et al. Chronic intermittent hypoxia augments chemoreflex control of sympathetic activity: role of the angiotensin II type 1 receptor. Respir Physiol Neurobiol 2010; 171: 36-45.

47 Sharpe AL, Calderon AS, Andrade MA, et al. Chronic intermittent hypoxia increases sympathetic control of blood pressure: role of neuronal activity in the hypothalamic paraventricular nucleus. Am J Physiol Heart Circ Physiol 2013; 305: H1772-H1780.

48 Silva AQ, Schreihofer AM. Altered sympathetic reflexes and vascular reactivity in rats after exposure to chronic intermittent hypoxia. J Physiol 2011; 589: 1463-1476.

49 Dempsey JA, Veasey SC, Morgan BJ, et al. Pathophysiology of sleep apnea. Physiol Rev 2010; 90: 47-112.

50 Iturriaga R, Moya EA, Del Rio R. Carotid body potentiation induced by intermittent hypoxia: implications for cardiorespiratory changes induced by sleep apnoea. Clin Exp Pharmacol Physiol 2009; 36: 1197-1204.

51 Porzionato A, Macchi V, De Caro R, et al. Inflammatory and immunomodulatory mechanisms in the carotid body. Respir Physiol Neurobiol 2013; 187: 31-40.

52 Fletcher EC, Orolinova N, Bader M. Blood pressure response to chronic episodic hypoxia: the renin-angiotensin system. J Appl Physiol 2002; 92: 627-633.

53 Liu JL, Irvine S, Reid IA, et al. Chronic exercise reduces sympathetic nerve activity in rabbits with pacing-induced heart failure: a role for angiotensin II. Circulation 2000; 102: 1854-1862.

54 Hoffman MS, Mitchell GS. Spinal 5-HT7 receptors and protein kinase A constrain intermittent hypoxia-induced phrenic long-term facilitation. Neuroscience 2013; 250: 632-643.

55 Ramirez JM, Mitchell GS. Clinical challenges to ventilatory control. Respir Physiol Neurobiol 2013; $189: 211-212$.

56 Tester NJ, Fuller DD, Fromm JS, et al. Long-term facilitation of ventilation in humans with chronic spinal cord injury. Am J Respir Crit Care Med 2014; 189: 57-65.

57 Forster HV, Haouzi P, Dempsey JA. Control of breathing during exercise. Compr Physiol 2012; 2: 743-777.

58 Dempsey JA, Blain GM, Amann M. Are type III-IV muscle afferents required for a normal steady-state exercise hyperpnoea in humans? J Physiol 2014; 592: 463-474.

59 Whipp BJ. Control of exercise hyperpnea: the unanswered question. In: Poulin M, Wilson R, eds. Integration of Respiratory Control. New York, Springer, 2008; pp. 16-24.

60 Krogh A, Lindhard J. The regulation of respiration and circulation during the initial stages of muscular work. J Physiol 1913; 47: 112-136.

61 Thornton JM, Guz A, Murphy K, et al. Identification of higher brain centres that may encode the cardiorespiratory response to exercise in humans. J Physiol 2001; 533: 823-836.

62 Williamson JW, McColl R, Mathews D, et al. Brain activation by central command during actual and imagined handgrip under hypnosis. J Appl Physiol 2002; 92: 1317-1324.

63 Galbo H, Kjaer M, Secher NH. Cardiovascular, ventilatory and catecholamine responses to maximal dynamic exercise in partially curarized man. I Physiol 1987; 389: 557-568.

64 Amann M, Proctor LT, Sebranek JJ, et al. Somatosensory feedback from the limbs exerts inhibitory influences on central neural drive during whole body endurance exercise. J Appl Physiol 2008; 105: 1714-1724.

65 Hornbein TF, Sorensen SC. Ventilatory response to hypoxia and hypercapnia in cats living at high altitude. $J$ Appl Physiol 1969; 27: 834-836. 
Goodwin GM, McCloskey DI, Mitchell JH. Cardiovascular and respiratory responses to changes in central command during isometric exercise at constant muscle tension. J Physiol 1972; 226: 173-190.

67 Eldridge FL, Millhorn DE, Waldrop TG. Exercise hyperpnea and locomotion: parallel activation from the hypothalamus. Science 1981; 211: 844-846.

68 Iwamoto GA, Wappel SM, Fox GM, et al. Identification of diencephalic and brainstem cardiorespiratory areas activated during exercise. Brain Res 1996; 726: 109-122.

69 Gandevia SC, Rothwell JC. Activation of the human diaphragm from the motor cortex. J Physiol 1987; 384: 109-118.

70 Green AL, Wang S, Owen SL, et al. Deep brain stimulation can regulate arterial blood pressure in awake humans. Neuroreport 2005; 16: 1741-1745.

71 Penfield W, Boldrey E. Somatic motor and sensory representation in the cerebral cortex of man as studied by electrical stimulation. Brain 1937; 60: 389-443.

72 Thornton JM, Aziz T, Schlugman D, et al. Electrical stimulation of the midbrain increases heart rate and arterial blood pressure in awake humans. J Physiol 2002; 539: 615-621.

73 Williamson JW, McColl R, Mathews D, et al. Hypnotic manipulation of effort sense during dynamic exercise: cardiovascular responses and brain activation. J Appl Physiol 2001; 90: 1392-1399.

74 Basnayake SD, Green AL, Paterson DJ. Mapping the central neurocircuitry that integrates the cardiovascular response to exercise in humans. Exp Physiol 2012; 97: 29-38.

75 Basnayake SD, Hyam JA, Pereira EA, et al. Identifying cardiovascular neurocircuitry involved in the exercise pressor reflex in humans using functional neurosurgery. J Appl Physiol 2011; 110: 881-891.

76 Paterson DJ. Defining the neurocircuitry of exercise hyperpnoea. J Physiol 2014; 592: 433-444

77 Hornbein TF, Sorensen SC, Parks CR. Role of muscle spindles in lower extremities in breathing during bicycle exercise. J Appl Physiol 1969; 27: 476-479.

78 Hill JM, Kaufman MP. Attenuation of reflex pressor and ventilatory responses to static muscular contraction by intrathecal opioids. J Appl Physiol 1990; 68: 2466-2472.

79 Amann M, Blain GM, Proctor LT, et al. Group III and IV muscle afferents contribute to ventilatory and cardiovascular response to rhythmic exercise in humans. J Appl Physiol 2010; 109: 966-976.

80 Amann M, Blain GM, Proctor LT, et al. Implications of group III and IV muscle afferents for high-intensity endurance exercise performance in humans. J Physiol 2011; 589: 5299-5309.

81 Amann M, Proctor LT, Sebranek JJ, et al. Opioid-mediated muscle afferents inhibit central motor drive and limit peripheral muscle fatigue development in humans. J Physiol 2009; 587: 271-283.

82 Haouzi P, Chenuel B, Huszczuk A. Sensing vascular distension in skeletal muscle by slow conducting afferent fibers: neurophysiological basis and implication for respiratory control. J Appl Physiol 2004; 96: 407-418.

83 Dempsey JA. New perspectives concerning feedback influences on cardiorespiratory control during rhythmic exercise and on exercise performance. J Physiol 2012; 590: 4129-4144.

84 Johnson BD, Reddan WG, Pegelow DF, et al. Flow limitation and regulation of functional residual capacity during exercise in a physically active aging population. Am Rev Respir Dis 1991; 143: 960-967.

85 Johnson BD, Reddan WG, Seow KC, et al. Mechanical constraints on exercise hyperpnea in a fit aging population. Am Rev Respir Dis 1991; 143: 968-977.

86 Miller JD, Dempsey JA. Pulmonary limitations to exercise performance: the effects of healthy ageing and COPD. In: Massaro D, Massaro GDC, Chambon P, eds. Lung Development and Regeneration. New York, Marcel Dekker, 2004; pp. 525-571.

87 O’Donnell DE, Revill SM, Webb KA. Dynamic hyperinflation and exercise intolerance in chronic obstructive pulmonary disease. Am J Respir Crit Care Med 2001; 164: 770-777.

88 Amann M, Regan MS, Kobitary M, et al. Impact of pulmonary system limitations on locomotor muscle fatigue in patients with COPD. Am J Physiol Regul Integr Comp Physiol 2010; 299: R314-R324.

89 O'Donnell DE, D'Arsigny C, Webb KA. Effects of hyperoxia on ventilatory limitation during exercise in advanced chronic obstructive pulmonary disease. Am J Respir Crit Care Med 2001; 163: 892-898.

90 Gagnon P, Bussières JS, Ribeiro F, et al. Influences of spinal anesthesia on exercise tolerance in patients with COPD. Am J Respir Crit Care Med 2012; 186: 606-615.

91 Maltais F, Simard AA, Simard C, et al. Oxidative capacity of the skeletal muscle and lactic acid kinetics during exercise in normal subjects and in patients with COPD. Am J Respir Crit Care Med 1996; 153: $288-293$.

92 van den Borst B, Slot IG, Hellwig VA, et al. Loss of quadriceps muscle oxidative phenotype and decreased endurance in patients with mild-to-moderate COPD. J Appl Physiol 2013; 114: 1319-1328.

93 Ribeiro F, Thériault ME, Debigaré R, et al. Should all patients with COPD be exercise trained? J Appl Physiol 2013; 114: $1300-1308$.

94 Johnson RL Jr. Gas exchange efficiency in congestive heart failure. Circulation 2000; 101: 2774-2776.

95 Olson LJ, Arruda-Olson AM, Somers VK, et al. Exercise oscillatory ventilation: instability of breathing control associated with advanced heart failure. Chest 2008; 133: 474-481.

96 Woods PR, Olson TP, Frantz RP, et al. Causes of breathing inefficiency during exercise in heart failure. J Card Fail 2010; 16: 835-842.

97 Dempsey JA. Crossing the apnoeic threshold: causes and consequences. Exp Physiol 2005; 90: 13-24.

98 Ponikowski PP, Chua TP, Francis DP, et al. Muscle ergoreceptor overactivity reflects deterioration in clinical status and cardiorespiratory reflex control in chronic heart failure. Circulation 2001; 104: 2324-2330.

99 Smith SA, Mitchell JH, Naseem RH, et al. Mechanoreflex mediates the exaggerated exercise pressor reflex in heart failure. Circulation 2005; 112: 2293-2300

100 Olson TP, Joyner MJ, Eisenach JH, et al. Influence of locomotor muscle afferent inhibition on the ventilatory response to exercise in heart failure. Exp Physiol 2014; 99: 414-426.

101 Olson TP, Frantz RP, Snyder EM, et al. Effects of acute changes in pulmonary wedge pressure on periodic breathing at rest in heart failure patients. Am Heart J 2007; 153: 104.e1-104.e7.

102 O’Donnell DE, D’Arsigny C, Raj S, et al. Ventilatory assistance improves exercise endurance in stable congestive heart failure. Am J Respir Crit Care Med 1999; 160: 1804-1811. 
103 Borghi-Silva A, Carrascosa C, Oliveira CC, et al. Effects of respiratory muscle unloading on leg muscle oxygenation and blood volume during high-intensity exercise in chronic heart failure. Am J Physiol Heart Circ Physiol 2008; 294: $\mathrm{H} 2465-\mathrm{H} 2472$

104 Olson TP, Joyner MJ, Dietz NM, et al. Effects of respiratory muscle work on blood flow distribution during exercise in heart failure. J Physiol 2010; 588: 2487-2501.

105 Miller JD, Smith CA, Hemauer SJ, et al. The effects of inspiratory intrathoracic pressure production on the cardiovascular response to submaximal exercise in health and chronic heart failure. Am J Physiol Heart Circ Physiol 2007; 292: H580-H592.

106 Harms CA, Wetter TJ, McClaran SR, et al. Effects of respiratory muscle work on cardiac output and its distribution during maximal exercise. J Appl Physiol 1998; 85: 609-618.

107 Stickland MK, Miller JD, Smith CA, et al. Carotid chemoreceptor modulation of regional blood flow distribution during exercise in health and chronic heart failure. Circ Res 2007; 100: 1371-1378.

108 Wang HJ, Li YL, Zucker IH, et al. Exercise training prevents skeletal muscle afferent sensitization in rats with chronic heart failure. Am J Physiol Regul Integr Comp Physiol 2012; 302: R1260-R1270.

109 Zurek M, Corrà U, Piepoli MF, et al. Exercise training reverses exertional oscillatory ventilation in heart failure patients. Eur Respir J 2012; 40: 1238-1244.

110 Chiappa GR, Roseguini BT, Vieira PJ, et al. Inspiratory muscle training improves blood flow to resting and exercising limbs in patients with chronic heart failure. J Am Coll Cardiol 2008; 51: 1663-1671.

111 Jaenisch RB, Hentschke VS, Quagliotto E, et al. Respiratory muscle training improves hemodynamics, autonomic function, baroreceptor sensitivity, and respiratory mechanics in rats with heart failure. J Appl Physiol 2011; 111: $1664-1670$.

112 Piper AJ, Grunstein RR. Big breathing: the complex interaction of obesity, hypoventilation, weight loss, and respiratory function. J Appl Physiol 2010; 108: 199-205.

113 Javaheri S, Dempsey JA. Central sleep apnea. Compr Physiol 2013; 3: 141-163.

114 Eckert DJ, White DP, Jordan AS, et al. Defining phenotypic causes of obstructive sleep apnea. Identification of novel therapeutic targets. Am J Respir Crit Care Med 2013; 188: 996-1004.

115 Younes M. Role of respiratory control mechanisms in the pathogenesis of obstructive sleep disorders. J Appl Physiol 2008; 105: 1389-1405.

116 Haxhiu MA, van Lunteren E, Mitra J, et al. Comparison of the response of diaphragm and upper airway dilating muscle activity in sleeping cats. Respir Physiol 1987; 70: 183-193.

117 Horner RL, Liu X, Gill H, et al. Effects of sleep-wake state on the genioglossus vs. diaphragm muscle response to $\mathrm{CO}_{2}$ in rats. J Appl Physiol 2002; 92: 878-887.

118 Hudgel DW, Chapman KR, Faulks C, et al. Changes in inspiratory muscle electrical activity and upper airway resistance during periodic breathing induced by hypoxia during sleep. Am Rev Respir Dis 1987; 135: 899-906.

119 Warner G, Skatrud JB, Dempsey JA. Effect of hypoxia-induced periodic breathing on upper airway obstruction during sleep. J Appl Physiol 1987; 62: 2201-2211.

120 Xie A, Teodorescu M, Pegelow DF, et al. Effects of stabilizing or increasing respiratory motor outputs on obstructive sleep apnea. J Appl Physiol 2013; 115: 22-33.

121 Isono S, Remmers JE, Tanaka A, et al. Anatomy of pharynx in patients with obstructive sleep apnea and in normal subjects. J Appl Physiol 1997; 82: 1319-1326.

122 Younes M. Contributions of upper airway mechanics and control mechanisms to severity of obstructive apnea. Am J Respir Crit Care Med 2003; 168: 645-658.

123 Edwards BA, Sands SA, Eckert DJ, et al. Acetazolamide improves loop gain but not the other physiological traits causing obstructive sleep apnoea. J Physiol 2012; 590: 1199-1211.

124 Wellman A, Jordan AS, Malhotra A, et al. Ventilatory control and airway anatomy in obstructive sleep apnea. Am J Respir Crit Care Med 2004; 170: 1225-1232.

125 Wellman A, Malhotra A, Jordan AS, et al. Effect of oxygen in obstructive sleep apnea: role of loop gain. Respir Physiol Neurobiol 2008; 162: 144-151.

126 Weaver TE, Grunstein RR. Adherence to continuous positive airway pressure therapy: the challenge to effective treatment. Proc Am Thorac Soc 2008; 5: 173-178.

127 Javaheri S. Acetazolamide improves central sleep apnea in heart failure: a double-blind, prospective study. Am J Respir Crit Care Med 2006; 173: 234-237.

128 Berry RB, Kouchi K, Bower J, et al. Triazolam in patients with obstructive sleep apnea. Am J Respir Crit Care Med 1995; 151: 450-454.

129 Bonora M, St John WM, Bledsoe TA. Differential elevation by protriptyline and depression by diazepam of upper airway respiratory motor activity. Am Rev Respir Dis 1985; 131: 41-45.

130 Eckert DJ, Owens RL, Kehlmann GB, et al. Eszopiclone increases the respiratory arousal threshold and lowers the apnoea/hypopnoea index in obstructive sleep apnoea patients with a low arousal threshold. Clin Sci (Lond) 2011; 120: 505-514.

131 Chowdhuri S, Ghabsha A, Sinha P, et al. Treatment of central sleep apnea in U.S. veterans. J Clin Sleep Med 2012; 8: 555-563.

132 Gilmartin G, McGeehan B, Vigneault K, et al. Treatment of positive airway pressure treatment-associated respiratory instability with enhanced expiratory rebreathing space (EERS). J Clin Sleep Med 2010; 6: 529-538.

133 Thomas RJ, Rosen BR, Stern CE, et al. Functional imaging of working memory in obstructive sleep-disordered breathing. J Appl Physiol 2005; 98: 2226-2234.

134 Wellman A, Edwards BA, Sands SA, et al. A simplified method for determining phenotypic traits in patients with obstructive sleep apnea. J Appl Physiol 2013; 114: 911-922.

135 Eastwood PR, Barnes M, Walsh JH, et al. Treating obstructive sleep apnea with hypoglossal nerve stimulation. Sleep 2011; 34: 1479-1486.

136 Strollo PJ Jr, Soose RJ, Maurer JT, et al. Upper-airway stimulation for obstructive sleep apnea. N Engl J Med 2014; 370: 139-149.

137 Niewinski P, Janczak D, Rucinski A, et al. Carotid body removal for treatment of chronic systolic heart failure. Int J Cardiol 2013; 168: 2506-2509. 
138 Paton JF, Sobotka PA, Fudim M, et al. The carotid body as a therapeutic target for the treatment of sympathetically mediated diseases. Hypertension 2013; 61: 5-13.

139 Nakayama K. Surgical removal of the carotid body for bronchial asthma. Dis Chest 1961; 40: 595-604.

140 Marcus NJ, Del Rio R, Schultz EP, et al. Carotid body denervation improves autonomic and cardiac function and attenuates disordered breathing in congestive heart failure. J Physiol 2014; 592: 391-408.

141 Abdala AP, McBryde FD, Marina N, et al. Hypertension is critically dependent on the carotid body input in the spontaneously hypertensive rat. J Physiol 2012; 590: 4269-4277.

142 Ribeiro MJ, Sacramento JF, Gonzalez C, et al. Carotid body denervation prevents the development of insulin resistance and hypertension induced by hypercaloric diets. Diabetes 2013; 62: 2905-2916.

143 Del Rio R, Marcus NJ, Schultz HD. Carotid chemoreceptor ablation improves survival in heart failure: rescuing autonomic control of cardiorespiratory function. J Am Coll Cardiol 2013; 62: 2422-2430.

144 Lesske J, Fletcher EC, Bao G, et al. Hypertension caused by chronic intermittent hypoxia-influence of chemoreceptors and sympathetic nervous system. J Hypertens 1997; 15: 1593-1603.

145 Del Rio R, Marcus NJ, Schultz HD. Inhibition of hydrogen sulfide restores normal breathing stability and improves autonomic control during experimental heart failure. J Appl Physiol 2013; 114: 1141-1150.

146 Timmers HJ, Wieling W, Karemaker JM, et al. Denervation of carotid baro- and chemoreceptors in humans. J Physiol 2003; 553: 3-11.

147 Skatrud JB, Dempsey JA, Bhansali P, et al. Determinants of chronic carbon dioxide retention and its correction in humans. J Clin Invest 1980; 65: 813-821.

148 Davies EJ, Moxham T, Rees K, et al. Exercise training for systolic heart failure: Cochrane systematic review and meta-analysis. Eur J Heart Fail 2010; 12: 706-715.

149 Johnson BD, Joyner MJ. Carotid body denervation: too soon to get breathless about heart failure? J Am Coll Cardiol 2013; 62: 2431-2432.

150 Mousa TM, Liu D, Cornish KG, et al. Exercise training enhances baroreflex sensitivity by an angiotensin IIdependent mechanism in chronic heart failure. J Appl Physiol 2008; 104: 616-624.

151 Tasoulis A, Papazachou O, Dimopoulos S, et al. Effects of interval exercise training on respiratory drive in patients with chronic heart failure. Respir Med 2010; 104: 1557-1565. 